\title{
Bare coordination: the semantic shift
}

\author{
Bert Le Bruyn · Henriëtte de Swart
}

Received: 4 October 2011 / Accepted: 24 November 2012 / Published online: 30 April 2014

(C) The Author(s) 2014. This article is published with open access at Springerlink.com

\begin{abstract}
This paper develops an analysis of the syntax-semantics interface of two types of split coordination structures. In the first type, two bare singular count nouns appear as arguments in a coordinated structure, as in bride and groom were happy. We call this the N\&N construction. In the second type, the determiner shows agreement with the first conjunct, while the second conjunct is bare, as in the Spanish example el hornero y hornera cobraban en panes ('the ${ }_{\mathrm{sg} . \mathrm{m}}$ baker $_{\mathrm{sg} . \mathrm{m}}$ and baker $\mathrm{s}_{\mathrm{sg} . \mathrm{f}}$ were $_{\mathrm{pl}}$ paid in bread loaves'). We call this the DN\&N construction. Both N\&N and DN\&N constructions are common in languages that otherwise require an article or determiner on singular count nouns in regular argument position, and give rise to 'split' readings that cannot be accounted for by the standard semantics of conjunction in terms of set intersection. Furthermore, they are restricted to instances of 'natural' coordination.

We formalize the semantics of split conjunction in terms of intersection between sets of matching pairs, which correlates with the lexical semantics and pragmatics of natural coordination. We maintain that an N\&N construction gets either a definite or an indefinite interpretation by covert type-shifting, because projection of an article ranging over the coordination as a whole is blocked in languages like English and Spanish. For DN\&N structures, we propose a syntactic structure in which D is in construction with the first conjunct. Coordination with a second, bare conjunct requires a covert type-shift that is licensed only under the special matchmaking semantics of conjunction. The analysis addresses a range of issues these coordinate structures raise about syntactic and semantic agreement, in particular with respect to number. Next to English and Spanish we will look into Dutch and French in detail.
\end{abstract}

B. Le Bruyn $(\varangle) \cdot$ H. de Swart Utrecht Institute of Linguistics-OTS, Trans 10, 3512JK, Utrecht, The Netherlands e-mail: b.s.w.lebruyn@uu.nl

H. de Swart

e-mail: h.deswart@uu.nl 
Keywords Coordination · Bare nominal · Type shift · Definite/indefinite ·

Agreement

\section{Bare coordination constructions}

In this paper we propose a new analysis of the syntax-semantics interface in two types of bare coordination. In the first type, two bare nouns appear as arguments in a coordinated structure, as illustrated in (1). The example in (1a) is from Heycock and Zamparelli (2003), the Spanish example in (1b) is from Camacho (2003:24), the French example in (1c) has been remodeled after an attested example, and the Dutch example in (1d) is from Zwarts (2009).

(1) a. A black cat and a brown dog were fighting in the street. Cat and dog were equally filthy.

b. Perro y gato andaban sueltos.

[Spanish] dog and cat roamed $_{\mathrm{pl}}$ loose $_{\mathrm{pl}}$

'Dog and cat roamed freely.'

c. Cela fait deux ans que Martine attend une greffe de rein. Son demi-frère Jean-Pierre est prêt à lui faire don d'un rein. Or, un blocage administratif lui refuse ce sacrifice. Frère et soeur ont décidé de se tourner vers le ministre de la Santé pour trancher le conflit.

[French] 'For two years now, Martine is waiting for a kidney transplant. Her halfbrother Jean-Pierre is ready to donate a kidney. However, an administrative rejection renders it impossible for him to make this sacrifice. Brother and sister turned to the minister of Health to resolve the conflict.'

d. En nu dreigt onze generaal ster en erekruis te moeten And now threatens our general star and cross of honour to must missen.

[Dutch] miss

'And now our general is in danger of having to miss star and cross of honour.'

Such coordinate structures are unusual, because languages like English, Spanish and Dutch normally require an article or other determiner on singular count nouns in regular argument position. ${ }^{1}$ The fact that we find bare count nouns in coordination makes this a "bare construction" in the sense of de Swart and Zwarts (2009), along with bare predication, bare prepositional phrases, bare titles, bare noun incorporation, etc. Bare

\footnotetext{
${ }^{1}$ In this paper, we take it for granted that a lexical distinction between count and mass nouns can be established for bare nouns. In ongoing work, we defend this claim based on empirical evidence coming from bare nouns in prepositional environments (cf. Le Bruyn et al. 2011 for a first sketch). Obviously, this does not mean that count nouns such as house cannot be coerced to get a mass reading, as in (i) (from http://en.wikipedia.org/wiki/Mass_noun):
}

(i) You get a lot of house for your money since the recession.

However, the examples in this paper are set up in such a way that mass interpretations are unlikely in the context. 
constructions raise special questions concerning the syntax-semantics interface, as evidenced by the extensive literature on predication and incorporation constructions. The investigation of bare coordination is thus part of a larger study of constructions that display unexpected article drop. Here we call the type of bare coordination illustrated in (1) the N\&N construction, to emphasize the lack of an overt DP projection.

In the second type of bare coordination, there is a determiner which shows agreement in number and gender (in languages where this is relevant) with the first conjunct, while the second conjunct appears bare. We illustrate with the English examples in (2a) and (b) from Heycock and Zamparelli (2005), the Spanish example in (2c) from Demonte et al. (2011), the Portuguese example in (3d) from de Almeida Torres (1981), and the Dutch example in (2e) from Heycock and Zamparelli (2005) (quoted from Jack Hoeksema p.c.).
a. A man and woman are in love.
b. This soldier and sailor are inseparable.
c. El hornero y hornera cobraban en panes.
the $_{\text {sg.m }}$ baker $_{\text {sg.m }}$ and baker $_{\text {sg.f }}$ were.paid in bread.loaves
[Spanish]
'The baker and baker woman were paid in bread loaves.'
d. no povo e gente hebreia
on.the $_{\text {sg.m }}$ population $_{\text {sg.m }}$ and people sg.f $_{\text {febrew }}$ sg.f
'on the Hebrew population and people'
e. Deze man en vrouw zijn gescheiden.
this man and woman are divorced
[Dutch]
'This man and woman are divorced (not necessarily from each other).'

These constructions are well known in the syntactic literature for their mismatch in agreement features and have been used to argue in favour of two types of number features: one taking care of agreement on D (concord features) and one taking care of agreement on the verb (index features). As pointed out by King and Dalrymple (2004), agreement on the verb must be plural (3a), but agreement on the determiner must be singular (3b):

(3) a. This boy and girl are/*is eating pizza.

b. this boy and girl/*these boy and girl/*this boy and girls/*these boys and girl

King and Dalrymple (2004) maintain that determiner agreement is not an instance of closest conjunct agreement, because of the ungrammaticality of *this boy and girls and *these boys and girl. Arnold et al. (2006), Demonte et al. (2011), and Demonte and Pérez-Jiménez (2012) reject King and Dalrymple's claim, and maintain that gender agreement as in the Spanish and Portuguese examples (2c) and (2d), but also the number agreement pattern in examples like (54c) and (54d) below, can only be accounted for in terms of closest conjunct agreement. In line with their views, we will analyze agreement on the determiner in examples like (2) in terms of closest conjunct agreement. In order to distinguish the constructions in (2) from the bare coordination cases in (1), we will label them DN\&N constructions. The term emphasizes the presence of a DP projection, but marks the second conjunct as a bare nominal that we will take to be an NP. 
The data in (1) and (2) raise a number of issues concerning the syntax, semantics and pragmatics of bare coordination structures that we address in this paper. Some of them relate to coordination structures more in general (cf. Haspelmath 2007; Zamparelli 2011 for recent overviews); others are specific to bare coordination. The paper starts with N\&N constructions. Heycock and Zamparelli (2003) and Roodenburg $(2004,2005)$ claim that bare singulars in N\&N constructions are necessarily interpreted as definite, but Sect. 2 shows that this is empirically incorrect. The starting point of our analysis is thus the claim that singular and plural bare coordinated nouns acquire both a definite and an indefinite interpretation depending on the context.

We agree with Heycock and Zamparelli (2003) that N\&N constructions involve a special semantics of conjunction. Section 3 develops a matchmaking analysis of conjunction, which is a variation on the analysis proposed by Heycock and Zamparelli (2003), but one that has broader applications, as will be seen in Sect. 6. The matchmaking analysis accounts for the natural coordination effects as part of the lexicon and pragmatics (Sect. 4).

In Sect. 5 we analyze N\&N structures as bare plurals, and claim the CoordP as a whole lacks a DP projection. This analysis deviates from the proposals made by Heycock and Zamparelli (2003), but is in line with Roodenburg (2004, 2005). We exploit the optimality-theoretic (OT) typology developed by de Swart and Zwarts (2008, 2010) to formalize our insights about the syntactic structure of N\&N constructions in English, Dutch, and Spanish. OT constraints are subject to reranking, so the analysis can deal with typological variation (cf. King and Dalrymple 2004).

At first sight, DN\&N constructions raise serious problems for the OT analysis. The overt presence of an article in examples like (2) indicates that these coordinate structures involve a DP projection. Existing analyses of DN\&N constructions propose different explanations of the agreement mismatches, but they all assume a DP projection on top of the coordination, where the article is located (cf. King and Dalrymple 2004; Heycock and Zamparelli 2005; Demonte and Pérez-Jiménez 2012). Obviously, if the bareness of N\&N constructions is explained by the lack of a DP projection on top of the coordinate phrase, this constituent structure is incompatible with the syntactic analysis developed in Sect. 5. Therefore, Sect. 6 explores an alternative analysis on the basis of the asymmetric coordination structure [CoordP [DP D NP] and NP]. The assumption that $\mathrm{D}$ is in construction with the first conjunct in DN\&N constructions accounts in a natural way for closest conjunct agreement, but raises an important semantic question concerning the type mismatch between the two conjuncts. We adopt a type-shifting analysis of the second conjunct, and take the covert type-shift to be licensed only under the special matchmaking semantics of conjunction developed in Sect. 3. We also investigate some complex agreement patterns with adjectival modifiers on the first or the second conjunct.

\section{The $N \& N$ construction: facts and previous analyses}

Given that the facts we base our analysis on are somewhat different from those underlying Heycock and Zamparelli (2003, 2005) and Roodenburg (2004, 2005), we start with a presentation of the descriptive features of N\&N constructions, and their 
implications for the theory. We investigate split readings (Sect. 2.1), definiteness (Sect. 2.2), and the existential interpretation of bare plurals (Sect. 2.3) and bare singulars (Sect. 2.4). The empirical line of argumentation will lead us to reject the restriction to definite readings by providing examples of coordinated bare singulars with an indefinite interpretation. That data point leads us to reject an empty D analysis of split coordination. Instead, we propose to analyze N\&N constructions as bare plurals lacking a DP projection. The semantics, pragmatics, and syntax of N\&N constructions are then further worked out in Sects. 3-5.

\subsection{Joint and split coordination}

There are two ways of coordinating properties in natural language. Examples (4) and (5) illustrate them in the verbal and the nominal domain respectively:

(5) We met a friend and colleague of Mary's yesterday.

a. She wants to go out for dinner with us tonight.

b. They want to go out for dinner with us tonight.

Both (4) and (5) allow for two readings. For (4), the first reading is that both John and Mary sang and danced, the second that John sang and Mary danced (or vice versa). For (5) the first reading is that we met an individual that is both a friend and a colleague of Mary's, the second that we met an individual that is a friend of Mary's and an individual that is a colleague of Mary's. Singular and plural pronouns and corresponding verb agreement in the subsequent sentences (5a) and (b) make the two readings explicit. We will refer to the first (intersective) reading as the "joint" interpretation, and to the second (non-intersective) reading as the "split" interpretation. Occasionally, we will also refer to coordinations with a joint/split interpretation as joint/split coordinations. ${ }^{2}$

The standard semantics of conjunction handles joint coordination in terms of set intersection. The split readings are difficult to deal with in this paradigm, as already pointed out by Partee and Rooth (1983), who refer to observations made by Cooper (1979). This paper focuses on the split reading of conjunction in the nominal domain, so it is concerned with the interpretation of examples like (5) in which the two conjuncts refer to different individuals, as in (5b).

While DN\&N constructions allow both split and joint interpretations, N\&N constructions are restricted to a split interpretation. Given that plurals easily give rise to sloppy readings and judgments are less clear-cut, we illustrate with bare singulars in English (6) and French (7).

(6) a. Yesterday Peter came to visit me and brought along a guardian and a close confidant of mine.

'Peter was in a cheerful mood but guardian and confidant were not.'

\footnotetext{
${ }^{2}$ In this paper, we ignore other major distinctions such as the difference between Boolean and non-Boolean coordination, issues concerning distributivity and scope (cf. Winter 2001 and references therein).
} 
b. Yesterday Peter came to visit me and brought along a guardian and close confidant of mine.

*'Peter was in a cheerful mood but guardian and confidant was not.'

a. Hier, nous avons rencontré Marie qui était accompagnée d' un Yesterday, we have met Marie who was accompanied of a ami et un collègue à nous. Marie était heureuse de nous voir mais friend and a colleague to us. Marie was happy of us see but collègue et ami ne l' étaient pas. colleague and friend NEG it were NEG.

b. Hier, nous avons rencontré Marie qui était accompagnée d' un Yesterday, we have met Marie who was accompanied of a ami et collègue à nous. *Marie était heureuse de nous voir mais friend and colleague to us. Marie was happy of us see but collègue et ami ne l'était pas. colleague and friend NEG it was NEG.

Some native speakers perceive (6a) and (7a) as slightly unusual, but the examples show a clear contrast with (6b) and (7b), which are downright ungrammatical. The difference between them resides in the fact that we have used agreement on the verb to force a split reading in the (a) variants and a joint reading in the (b) variants. The contrast provides strong evidence for the claim that bare coordination is only possible when split interpretations are involved. An explanatory analysis of N\&N and DN\&N constructions has to account for the contrast in availability of split and joint readings in (5) and (6/7).

\subsection{Definite interpretations of bare coordinate structures}

Heycock and Zamparelli (2003) maintain that bare singulars and plurals in coordinate structures in English can get a definite interpretation, and provide the examples in (8) and (9) to support their view. We can also see the definite (possessive) interpretation in the Dutch example (1d). Additional Dutch and Spanish examples, modified from attested corpus examples are in (10)/(11) and (12)/(13).

(8) We had to set the table for the queen. We arranged one crystal goblet, one silver spoon, two antique gold forks and two platinum knives. Goblet and spoon were set on the right of the plate.

(Heycock and Zamparelli 2003)

(9) We had to set the table for the queen. We arranged one crystal goblet, one silver spoon, two antique gold forks and two platinum knives. Forks and knives were equally dirty.

(Heycock and Zamparelli 2003)

(10) Een meisje van slechts 10 jaar oud heeft een kerngezonde baby op de wereld gezet. (...) Moeder en kind maken het goed.

[Dutch]

'A 10 year old girl gave birth to a healthy baby. (...) Mother and child are well.'

(11) [about a healthy diet campaign targeting families with children]

In totaal hebben 529 kinderen van 7 tot 12 jaar en één van hun ouders/verzorgers aan het onderzoek deelgenomen. Evenals de kinderen zijn 
ouders erg positief over de campagne. Ouders en kinderen zijn volgens eigen zeggen geïnspireerd en aan het denken gezet.

'All in all, 529 children between 7 and 11 years old and one of their parents/caretakers participated in the project. Just like the children, the parents are very positive about the campaign. Parents and children have been inspired, and made to think (about healthy food), they say.'

(12) [about Juana and Juanita in the novel Juanita la Larga]

Toda la noche [...] madre e hija permanecieron en la plaza.

'The whole night [...] mother and daughter remained in the square.'

(13) Los padres de familia acudieron en masa para comprar cuadernos, guardapolvos y zapatos para sus hijos. Disgustados y preocupados porque el dinero no alcanza, padres e hijos fueron a los principales comercios para conseguir los útiles.

[Spanish]

'Parents flocked to buy notebooks, overalls and shoes for their children. Annoyed and worried that the money wouldn't be sufficient, parents and children went to the main stores to get supplies.'

Interestingly, Roodenburg $(2004,2005)$ extends these observations to French, a language which is well known for its lack of bare plurals. He provides the examples in (14) and (15):

Un chien et un chat étaient en train de se

battre dans notre a dog and a cat were busy each.other fighting in our jardin. Chien et chat avaient tous deux l' air sale. garden. Dog and cat had each two the air dirty 'A cat and dog were fighting in our garden. Cat and dog both looked dirty.'

(15) Nous étions en train de mettre la table pour la reine. Nous avons pris We were busy to lay the table for the queen. We have taken un gobelet en cristal, une cuillère d' argent, deux fourchettes d' or et a goblet in crystal, a spoon of silver two forks of gold and deux couteaux en platine. Fourchettes et couteaux étaient également two knives in platinum. Forks and knives were equally sales.

dirty

'We were laying the table for the queen. We took a crystal goblet, a silver spoon, two golden forks and two platinum knives. Forks and knives were equally dirty.'

In the examples (8)-(15), both conjuncts refer back to discourse referents introduced in the earlier discourse, which supports the claim that N\&N constructions get a definite interpretation. Heycock and Zamparelli (2003) posit the structure [DP $\mathrm{D}^{e}$ [CoordP $\mathrm{NP}$ and NP]] for N\&N constructions. They take movement of the CoordP to [Spec, $\mathrm{DP}]$ to be one of the configurations that can license the empty D. They furthermore assume this option is available to both coordinated bare plurals and coordinated bare singulars and leads to a definite interpretation. These assumptions derive the facts we have discussed in this section in a straightforward way, but they don't come for 
free. Given that Heycock and Zamparelli provide no independent syntactic evidence in favour of the presence of a null D nor for the movement from CoordP to [Spec, $\mathrm{DP}]$, their analysis is a theoretical construct that has to be justified by its predictive power.

In Heycock and Zamparelli's approach, the general availability of licensing by movement of the CoordP to [Spec, DP] contrasts with the reduced availability of another licensing configuration where the CoordP stays in situ, and gets an existential interpretation.

\subsection{Existential interpretations of coordinated bare plurals}

Heycock and Zamparelli assume existential interpretations of coordinate phrases to arise in situ, and claim that this configuration involves predication. They posit that predication is only available to coordinations of NPs that can independently function as predicates. Bare plurals (16a), but not bare singulars (16b) are free to occur in predicate position in English (16a): ${ }^{3}$
a. These are forks.
b. This is *(a) fork.
c. There are forks and knives on the table.

Under Heycock and Zamparalli's analysis, coordinated bare plurals in existential contexts like (16c) are felicitous, because bare plurals have a well-formed predicative use, as illustrated in (16a).

Example (16b) illustrates that bare singulars in the languages we look at don't function as predicates, so coordinated bare singulars are predicted to always move to [Spec, DP], and get a definite interpretation. Thus, there is a crucial contrast between $\mathrm{N} \& \mathrm{~N}$ constructions with bare plurals (which allow both definite and indefinite interpretations), and N\&N constructions with bare singulars (which only allow definite interpretations under the analysis advanced by Heycock and Zamparelli).

Their proposal has cross-linguistic validity. Examples (11) and (13) illustrated the definite interpretation of bare plurals in Dutch and Spanish. Examples (17) and (18) show that coordinated bare plurals in Spanish and Dutch can also get an existential interpretation:

\footnotetext{
${ }^{3}$ Heycock and Zamparelli are not concerned here with instances of well-formed bare predication as in (i) and (ii):
}

(i) Mary is chair of the department.

(ii) Hanna is advokaat.

[Dutch]

Hanna is lawyer

'Hanna is a lawyer.'

Given that our analysis of bare coordination does not rely on predication, we will not discuss here the feature-based analysis Heycock and Zamparelli develop of constructions like (i) and (ii). Compare the analysis we developed in de Swart et al. (2007) and Le Bruyn (2010) for further discussion and another analysis of bare predication. 
Le ha recordado al mundo entero que hay hombres $y$ to.him has reminded to-the world whole that there.is men and mujeres que no cejarán en el empeño de hacer justicia a los criminales women that not give.up in the obligation of do justice to the criminals políticos.

political

'He reminded the whole world that there are men and women who will not stop bringing political criminals to justice.'

(18) Er zijn ook ouders en kinderen die geen contact meer met elkaar hebben.

'There are also parents and children who are no longer in touch with each other.'

This is as expected, of course, as bare plurals in Spanish and Dutch are similar to English bare plurals in that they have a felicitous predicative use.

According to Roodenburg $(2004,2005)$, the existential interpretation of coordinate bare plurals is available in French as well:

Les voyageurs ne pouvaient pas bouger dans le métro ce matin. Chômeurs et cégétistes avaient envahi les rames pour se rendre à une manifestation.

'The passengers couldn't move their body in the subway this morning.

Unemployed and trade-union members had entered the carriages in order to go to a demonstration.'

Chômeurs and cégétistes have not been mentioned in the discourse before, so they get an existential (discourse new), rather than a definite (familiar) interpretation. This result is rather surprising, because bare plurals, just like bare singulars, are excluded from regular predicate position in French, as illustrated in (20a) and (b):
a. $\quad$ Ceci sont $*($ des $)$
fourchettes.
These are *(INDEF-PL) forks
b. Ceci est *(une) fourchette.
This is $*(a)$ fork

If neither bare singulars nor bare plurals have a felicitous predicative use in French, we expect coordinated bare plurals to be restricted to the definite interpretation illustrated in (15) above. We agree with Roodenburg that examples like (19) are felicitous in French, and confirm his observations by embedding the coordinated bare plural in an existential context:

Quand il y a enfants et animaux, je ralentis toujours. when there is children and animals, I slow.down always 'Whenever there are children and animals, I always slow down.'

According to Roodenburg $(2004,2005)$, the availability of an existential interpretation in (19) and (21) cannot be due to the predicative status of bare plurals, because this reading is blocked in French, as illustrated in (20a). Instead, Roodenburg maintains that coordination is responsible for semantic plurality, and bare plurals are permitted in regular argument position. He follows Delfitto and Schroten (1991) in their 
assumption that plural marking in French is not realized on the noun itself, but only on an external element. This is often the determiner, but it can also be the conjunction et. Coordination is then sufficient to license bare singulars as well as bare plurals in French. What looks like the definite interpretation of coordinate singulars in (8), (10), (12), and (14) is reanalyzed by Roodenburg as the 'strong' reading of bare plurals we find in examples like (22) (from Condoravdi 1994):

(22) Ghosts haunted the campus. Students were aware of the problem.

In contexts like (22), there is little difference in meaning between the bare plural 'students' and a definite plural 'the students': both globally cover the entire set of students on campus. If a definite-like interpretation is possible for bare plurals in contexts like (22), it is available in contexts like (9), (11), (13), and (15) as well. Under Roodenburg's analysis, movement is not necessary to obtain definiteness, because bare plurals in general are open to a strong quasi-universal reading.

We accept Roodenburg's view that semantic plurality is a crucial ingredient of N\&N constructions. Roodenburg proposes the syntactic structure of bare plurals for N\&N constructions, and we accept this. However, we would like to take his analysis one step further. Roodenburg uses semantic plurality as the unifying analysis of coordinate constructions, and claims that definite interpretations are really 'strong' indefinite readings. However, he does not account for the asymmetry between coordinated bare singulars and bare plurals. As bare plurals, coordinate bare singulars should tolerate definite ('strong indefinite') as well as existential ('weak indefinite') interpretations, just like bare plurals. But of course, Heycock and Zamparelli (2003) explicitly claim that weak indefinite readings of coordinated bare singulars are not available. Roodenburg does not contest this empirical generalization, but we will do so in Sect. 2.4.

\subsection{Existential interpretations of coordinated bare singulars}

Definite interpretations of bare count singulars in coordinate structures have been illustrated in (1a, c), (8), (10), (12), and (14). In Heycock and Zamparelli's analysis, such readings are derived under the special movement of CoordP to [Spec, DP] assumed for $\mathrm{N} \& \mathrm{~N}$ constructions, because this movement is claimed to be associated with definiteness. No in situ analysis of N\&N constructions involving bare singulars is available, because singular count nouns do not occur in regular predicate position in English (16b). So for Heycock and Zamparelli, it is crucial that bare singulars in $\mathrm{N} \& \mathrm{~N}$ constructions do not get an existential interpretation. However, existential interpretations are available, as the attested English, French, and Dutch examples in (23)-(26) show:

He had pad and pencil to picture the whole event.

Et là on arrive dans un village où il y a école et point d'eau. And there we arrive in a village where there is school and point of water

[French]

'And there we arrive in a village where there is a school and a well.' 
(25) Je kunt zelf je tijd indelen, er zijn geen vergaderingen nodig, en je kunt het gewoon thuis doen (mits je beschikt over computer en printer). [Dutch] 'You can organize your own time, no meetings are required, and you can work from home (if you have computer and printer).'

(26) [After you have been picked up from your hotel in Ho Chi Minh City you will drive to the Mekong Delta. After arriving in Ben Tre you will make a boat trip along some islands and fruit plantations.]

$\mathrm{U}$ vaart door het Xep kanaal en bereikt een klein eiland, waar paard en wagen u opwachten voor een rit langs de verschillende dorpjes.

[Dutch]

'You sail through the Xep canal and reach a small island, where horse and carriage await you for a trip along the different villages.'

In the examples in (23)-(25), coordinated bare singulars are embedded in an explicitly existential context. The object of a have verb in (23) and (25) is restricted to weak indefinites, as argued by Partee (1987), de Hoop (1996), de Swart (2001), and others. ${ }^{4}$ The complement of an existential there construction in (24) has a weak indefinite reading according to Milsark (1974), Barwise and Cooper (1981), Keenan (1987), McNally (1998); see McNally (2011) for an overview of the literature on existential sentences. Example (26) illustrates that existential interpretations of N\&N constructions are also available in subject position. ${ }^{5}$ We conclude that there is no asymmetry between bare singulars and bare plurals in the grammar of coordination:

\footnotetext{
${ }^{4}$ We can also find Spanish examples of this type, as in (i):
}

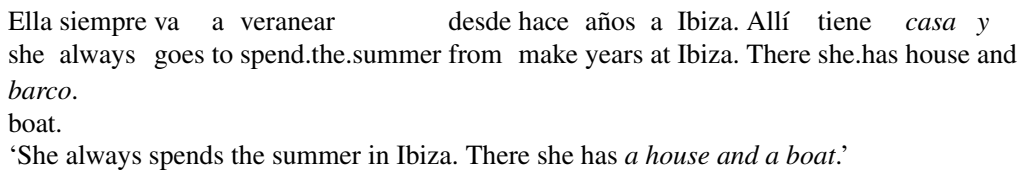

However, it is uncertain whether these have the same status as the bare coordination constructions in (23)-(25). The complement of a have verb or the existential hay construction tolerates bare singular count nouns more generally, as an instance of pseudo-incorporation, as observed by Espinal and McNally (2010). So the coordination data have little additional value. For this reason, arguments in favor of an existential interpretation of singulars in bare coordination structures should come from languages like English, Dutch, and French, rather than Spanish.

${ }^{5}$ An anonymous reviewer suggests that these examples are not truly indefinite, but can be explained away as quasi-universal readings. Example (23) would then mean something like, 'He had everything he needed to depict the event'. This idea is based on the quasi-universal interpretation of bare coordination we find in (i) (from Postma 1995):

(i) Het schip is met man en muis vergaan.

[Dutch]

the ship is with man and mouse perished

'The ship perished with everyone on board.'

Note that (i) is an idiomatic example, which may have non-compositional meaning ingredients that should not be compared to the productive constructions in (23)-(25). No quasi-universal reading is involved in these examples, as we can add information (ii) or insert a modifier that is compatible with an existential, but not a universal quantifier (iii):

(ii) He had pad and pencil to describe the event, but forgot to bring a camera, an omission which he later regretted bitterly. 
both are compatible with definite as well as indefinite interpretations. The empirical findings do not support Heycock and Zamparelli's syntactic analysis. Note that the examples are predominantly instances of so-called "natural" coordination, in which items are paired that are conventionally related in a lexical frame (cf. Sect. 4 below).

\subsection{Towards an analysis}

The issue of the syntax-semantics interface of $N \& N$ constructions has to be addressed anew based on the data presented in Sect. 2.4. Their bareness raises the question whether null determiners are involved. Heycock and Zamparelli postulate two different ways to license empty Ds. The movement of CoordP to [Spec, DP] leaves us with an empty $\mathrm{D}$ in a definite configuration. The prediction they make is that coordinated bare singulars in languages like English only get a definite interpretation whereas coordinated bare plurals can get both an indefinite and a definite interpretation. Given that we rejected their empirical generalization in Sect. 2.4, we can leave this type of null $\mathrm{D}$ aside.

The specific constraints Heycock and Zamparelli (2003) impose on licensing of the empty D under the existential reading of $\mathrm{N} \& \mathrm{~N}$ constructions are reminiscent of (but not identical to) Longobardi's (1994) approach. Longobardi (1994) and Stowell (1981) take the licensing of empty functional projections to depend on a lexical governor. This line of work would predict there to be a generalized subject/object asymmetry for coordinated bare nominals. This is however not what we get, as already illustrated by the acceptability of (26). We strengthen the argument by looking at Spanish coordinated bare plurals in contexts like (27) (from Laca 1999).

$$
\begin{aligned}
& \text { Hombres y mujeres iban y venían. } \\
& \text { men and women went and came }
\end{aligned}
$$

The existential interpretation of the N\&N construction in (27) is not available to Spanish bare plurals in preverbal subject position in general. Given that Spanish bare plu-

(iii) Je kunt zelf je tijd indelen, er zijn geen vergaderingen nodig, en je kunt het gewoon thuis doen (mits je minimaal/op z'n minst/tenminste/... beschikt over computer en printer).

'You can organize your own time, no meetings are required, and you can work from home (if you minimally/at the least/at least/... have computer and printer).'

Moreover, a counterpart of these examples in a non-bare coordination version requires the use of an indefinite (iv), not a definite (v) article:

(iv) He had a pad and a pencil to picture the event.

(v) \#He had the pad and the pencil to picture the event.

The example in (vi) is slightly modified from an attested example, and illustrates how coordinated indefinite singulars in the object position of a 'have' verb can also have an 'everything you need' reading, that is thus independent of bareness:

(vi) There was no money for art training, but as long as he had a pencil and a piece of paper, he was happy sketching the world around him.

These empirical arguments support the claim made in this section that we should take existential readings of coordinated bare singulars seriously in our grammar. 
rals are existential in meaning, their restriction to postverbal positions has been used as an argument in favour of an empty D. If there were an empty D in the coordination construction as well, we would expect (27) to be ungrammatical or marked. But Laca (1999) notes that existential examples of this type are fully grammatical and unmarked. So we would have to posit different licensing conditions on regular bare plurals and coordinated bare plurals in Spanish.

Most analyses that rely on null Ds use configurations in which a counterpart exists with an overt D. However, Sect. 5.1 will argue that this option is not available for bare coordination constructions. The lack of an overt counterpart sheds further doubt on the role of the null D. Independent evidence in favor of the special status of N\&N as a 'bare' construction comes from the observation that the conjuncts need to be bare Ns, and cannot be developed into NPs through adjectival modification. This creates a sharp contrast between bare singulars and bare plurals in coordinate structures. In DN\&N constructions, either the first or the second conjunct can be freely modified by an adjective $(28 \mathrm{a}, \mathrm{b})$ :
a. Colorful pastel illustrations portray the expressive mother and daughter in both thoughtful and playful moods.
b. The mother and younger daughter wore matching hats.
c. There were lots of complications at birth, but now mother and baby daughter are doing great.
d. Is it crucial for the communications to remain open between (*older/*experienced/*drunken) mother and (*younger/*happy/ *intelligent) daughter.

In $N \& N$ constructions, bare singulars can take a modifier that creates a subtype (28c), but subkind modifiers may be taken to adjoin at structurally lower levels than regular adjectives (cf. McNally and Boleda 2004). Crucially, other modifiers are ill-formed (28d). ${ }^{6}$ With bare plurals, no restrictions on adjectival modification apply in either construction $(29 a, b)$.

a. Yes, it's similar to the Joy Luck Club because the stories of the traditional mothers and Americanized daughters all intertwine, and the narrative is similar too, as entire chapters are devoted to each character.

b. The interaction between experienced mothers and pregnant daughters was a moment to cherish.

This is as expected, because English freely uses bare plurals in regular argument position, so coordinate constructions with bare plurals are no different from coordination of full DPs. The constraints on modification in (28) do not follow from the assumption of a null D, which entails the presence of a full nominal structure below the DP, which should therefore be compatible with all kinds of adjectival modification.

This leaves us with the last, and in fact weakest version of a null D in the syntactic structure of N\&N constructions. If we have to posit an indefinite null D that is not

\footnotetext{
${ }^{6}$ We note with Zwarts (2009) that there seems to be an asymmetry between modification following and preceding the noun, the former being more flexible than the latter. Probing this difference further would however lead us beyond the scope of this paper.
} 
subject to any licensing condition (as (26) and (27) would force us to do), we would at least expect that the null D predicts the definite or indefinite interpretation of the $\mathrm{N} \& \mathrm{~N}$ construction and the restrictions on modification. However, this is not the case, given the contrast between (28) and (29) and the observation that both definite and indefinite readings arise in both subject and object position, as we saw in Sect. 2.4.

As an anonymous reviewer suggests, we could remedy this problem if we assume that the null D simply receives the appropriate interpretation in the context. But if empty Ds are not subject to syntactic licensing restrictions, do not explain restrictions on modification, and do not predict the interpretation of the N\&N coordination, they are in fact inert. At that point, it does not matter whether we put the freedom of interpretation in the syntax (postulating truly vacuous null Ds) or in the semantics (postulating free existential/definite type-shifting interpretations), as the syntactic and semantic routes are equivalent. However, we prefer the semantic route, because it is simpler, and our proposals lead to a unified analysis of N\&N and DN\&N constructions.

Instead of postulating a null D analysis, we will develop Roodenburg's idea that N\&N constructions are bare plurals. Following Roodenburg, we propose a bare plural structure [CoordP $\mathrm{N}$ and $\mathrm{N}$ ] for N\&N constructions. The lack of a DP projection is an assumption that is also made for languages that have a fully productive bare nominal paradigm, compare Chierchia (1998) and Bošković (2008). In languages that lack definite/indefinite articles, nouns occur bare in regular argument position, and they are compatible with both a definite interpretation (uniquely referring and/or discourse familiar) and an indefinite (existential and/or discourse new) interpretation as the result of a covert type-shift (see Sect. 5 below on Mandarin Chinese and Russian, and Dayal 2011 for an overview of bare nominals across languages). In languages like English, French, Spanish and Dutch, articles are required for singular count nouns in regular argument position. However, the normal constraints on article use are lifted in $\mathrm{N} \& \mathrm{~N}$ constructions. In the absence of a definite or indefinite article for coordinate structures, N\&N constructions are compatible with both a definite and an existential interpretation by covert type-shifting.

The syntax of N\&N constructions as lacking a DP projection is worked out in Sect. 5. In order to establish the correlation between the syntax and semantics of N\&N constructions, we need to first get a better grip on the semantics of split conjunction. This will be the topic of Sect. 3. Section 4 investigates the connection of the semantics with the lexicon and pragmatics.

\section{The semantics of the $N \& N$ construction}

Section 2 gave an overview of the main descriptive features of $N \& N$ constructions. We observed that DN\&N constructions allow both joint and split readings (cf. (5)), but N\&N constructions are restricted to a split reading (cf. (6) and (7)). In this section we propose a polysemous semantics of coordination, which treats joint coordination as regular set intersection (Sect. 3.1), and split coordination as a case of intersection of sets of matching pairs (Sect. 3.2). 


\subsection{The semantics of joint coordination}

The semantics of joint coordination we assume is the standard set intersection semantics proposed by Partee and Rooth (1983):

$$
\llbracket \text { and }_{\text {joint }} \rrbracket=\lambda \mathrm{P} \lambda \mathrm{Q} \lambda \mathrm{x}(\mathrm{x} \in(\mathrm{Q} \cap \mathrm{P}))
$$

For two nominal predicates like friend and colleague, set intersection returns the set of individuals that are both friends and colleagues. For the joint reading of a friend and colleague, this leads to the following derivation:

$$
\begin{array}{ll}
\text { a. } & \llbracket \text { and }_{\text {joint }} \rrbracket=\lambda \mathrm{P} \lambda \mathrm{Q} \lambda \mathrm{x}(\mathrm{x} \in(\mathrm{Q} \cap \mathrm{P})) \\
\text { b. } & \llbracket \text { friend and } \mathrm{a}_{\text {joint }} \text { colleague }=\lambda \mathrm{x}(\mathrm{x} \in(\text { FRIEND } \cap \text { COLLEAGUE })) \\
\text { c. } & \llbracket \mathrm{a} \rrbracket=\lambda \mathrm{P} \lambda \mathrm{Q} \exists \mathrm{x}(\mathrm{P}(\mathrm{x}) \wedge \mathrm{Q}(\mathrm{x})) \\
\text { d. } & {\left[\mathrm{DP} \mathrm{a}\left[\text { CoordP friend and } \mathrm{d}_{\text {joint }} \text { colleague }\right]\right]=} \\
& \lambda \mathrm{Q} \exists \mathrm{x}(\mathrm{x} \in(\text { FRIEND } \cap \text { COLLEAGUE }) \wedge \mathrm{Q}(\mathrm{x}))
\end{array}
$$

Under the interpretation in (31), the standard semantics of coordination in terms of set intersection leads to the joint interpretation of and in which there is a single individual who has both properties.

The semantics of and joint in terms of standard set intersection immediately explains why $\mathrm{N} \& \mathrm{~N}$ constructions are not felicitous under this interpretation. Under the joint interpretation the coordinate noun friend and colleague is no different from a singular count noun like student, and we already know that such singular count nouns do not appear bare in regular argument position in a language like English. The OT analysis in Sect. 5 will formalize this insight.

If the joint reading of $N \& N$ constructions is blocked for grammatical reasons, the only interpretation they are licensed under is the split interpretation, which gives the coordinate noun phrase plural reference. The challenge is to enrich (30) in such a way that the split reading obtains as a special case of set intersection in a polysemous semantics of conjunction. A polysemous semantics is preferred over a homonymic analysis, because cross-linguistically the same coordinating elements are used for joint and split coordination (cf. Winter 2001; Heycock and Zamparelli 2003, 2005).

\subsection{The semantics of split coordination}

The semantics for split coordination we propose here is inspired by Heycock and Zamparelli's (2005) analysis in terms of set products, and personal discussions with Yoad Winter and Joost Zwarts. The formal definition is in (32):

$$
\llbracket \operatorname{and}_{\text {split }} \rrbracket=\lambda \mathrm{P} \lambda \mathrm{Q} \lambda \mathrm{z}(\mathrm{z} \in(\operatorname{RtoI}((\mathrm{Q} \times \mathrm{E}) \cap(\mathrm{E} \times \mathrm{P}))))
$$

With $E$ the universe, and RtoI the function of Relations to Individuals defined as follows: $\mathrm{RtoI}(\mathrm{R})=\{\mathrm{x} \oplus \mathrm{y}: \mathrm{R}(\mathrm{x}, \mathrm{y})\}$

The split interpretation of conjunction in (32) proceeds in two steps. The first part inserts set products, which replaces the set intersection based on the one-place predicates denoted by the two conjuncts with intersection between two two-place relations. The two-place relations are obtained by taking the product of the denotation of the 
first conjunct $\mathrm{Q}$ with the universe, and the product of $\mathrm{E}$ with the denotation of the second conjunct $\mathrm{P}$, as in (33):

$$
\begin{gathered}
\lambda \mathrm{P} \lambda \mathrm{Q} \lambda \mathrm{x}(\mathrm{x} \in(\mathrm{Q} \cap \mathrm{P})) \underset{\mathrm{P}}{\Rightarrow} \quad \lambda \mathrm{P}((\mathrm{Q} \times \underline{\mathrm{E}}) \cap(\underline{\mathrm{E} \times \mathrm{P})}) \\
\text { matchmaking } \quad \mathrm{E}=\text { universe }
\end{gathered}
$$

We refer to the enrichment in (33) as the matchmaking part, because it creates sets of pairs that match the two conjuncts. The second step is the mapping of the pairs of individuals built by the matchmaking relation onto sum individuals by the RtoI function defined in (32). The split interpretation of conjunction yields the set of sum individuals $\mathrm{x} \oplus \mathrm{y}$ that stand in a relation $\mathrm{R}$ such that the first member of the pair $(\mathrm{x}, \mathrm{y})$ related by $\mathrm{R}$ is in the denotation of the first conjunct, and the second member of the pair is in the denotation of the second conjunct.

To see how the interpretation of and $_{\text {split }}$ works for $N \& N$ constructions, let us spell out the interpretation of cat and dog were filthy in (34):

$$
\begin{array}{ll}
\text { a. } & \lambda \mathrm{P} \lambda \mathrm{Q}((\mathrm{Q} \times \mathrm{E}) \cap(\mathrm{E} \times \mathrm{P}))(c a t)(\text { dog }) \\
\text { b. } & (\mathrm{CAT} \times \mathrm{E}) \cap(\mathrm{E} \times \mathrm{DOG})=\mathrm{CAT} \times \mathrm{DOG} \\
\text { c. } & \mathrm{RtoI}(\mathrm{CAT} \times \mathrm{DOG})=\{\mathrm{x} \oplus \mathrm{y}: \mathrm{CAT} \times \operatorname{DOG}(\mathrm{x}, \mathrm{y})\} \\
\text { d. } & \iota \mathrm{x} \oplus \mathrm{y}(\mathrm{CAT} \times \mathrm{DOG}(\mathrm{x}, \mathrm{y})) \\
\text { e. } & \exists \mathrm{x} \oplus \mathrm{y}(\mathrm{CAT} \times \mathrm{DOG}(\mathrm{x}, \mathrm{y})) \\
\text { f. } & \text { Filthy } \mathrm{D}_{\mathrm{D}}(\iota \mathrm{x} \oplus \mathrm{y}(\mathrm{CAT} \times \mathrm{DOG}(\mathrm{x}, \mathrm{y})))
\end{array}
$$

In (34a), every individual in the set of cats is 'matched' to every individual in the universe and every individual in the universe is 'matched' to every individual in the set of dogs. The intersection of these two sets is the set of pairs such that the first member is a cat, and the second is a dog (34b). The function RtoI takes a relation and returns the set of (plural) individuals consisting of the individuals that make up the matching relation. When applied to (34b) this yields the set of plural individuals consisting of a cat and a dog in (34c). Given that coordinated bare singulars appear in regular argument position, we need an extra step to ensure argument status. In the absence of an overt D, a covert type-shift maps the set in (34c) onto a unique (familiar) or a newly introduced discourse referent as in (34d) or (34e). Example (34f) spells out the definite interpretation of cat and dog were filthy that is appropriate in the context given in (1a). We assume a distributive operator D to be associated with the predicate to be filthy. The existential interpretation of a coordinate bare noun in (34e) would be appropriate for the bare conjunctions in (23)-(26) in Sect. 2.4.

The essence of the matchmaking semantics is that one-place predicates are enriched to two-place relations, in such a way that the product is the result of intersection. This makes it straightforward to extend the analysis to relational nouns, which give rise to reciprocal readings in conjunction contexts (Staroverov 2007). ${ }^{7}$ That is,

\footnotetext{
${ }^{7}$ Staroverov (2007) is concerned with reciprocal readings of relational nouns in plural and conjunction contexts. However, his examples of conjunction are limited to DN\&N constructions such as a husband and wife, and he does not treat $\mathrm{N} \& \mathrm{~N}$ constructions. In a footnote, he points out that the reciprocal reading does not arise in full DN\&DN constructions such as a husband and a wife, but he does not work out the connection between bareness and enriched interpretation beyond this observation. Neither does he attempt to relate the reciprocal reading of relational nouns in conjunction contexts to natural coordination of bare nouns as in (34).
} 
the relational nouns brother and sister and mother and child in contexts like (1c) or (10) are interpreted as each other's brother and sister or mother and child. We can deal with such examples if we interpret the relational noun as a two-place relation, following De Bruin and Scha (1988). For bride and groom in (35), this leads to the two-place relations in (35a). Taking the intersection of these predicates would result in the empty set, because no one can be a bride and a groom at the same time. Borrowing an idea by Staroverov (2007), we take matchmaking with relational nouns to involve the inverse (or converse) relation of the second argument, as in (35b).

Bride and groom look happy.

a. $\quad \llbracket$ bride $_{<\mathrm{e},<\mathrm{e}, \mathrm{t}>>} \rrbracket=\{<\mathrm{a}, \mathrm{b}>\mid \operatorname{Bride}(\mathrm{a}, \mathrm{b})\}$

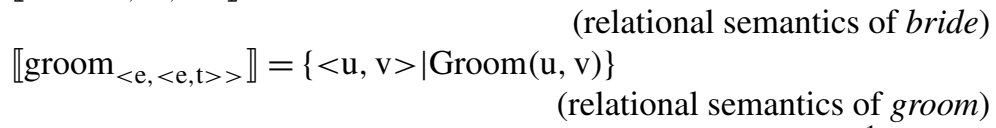

b. $\quad \lambda \mathrm{P} \lambda \mathrm{Q} \lambda \mathrm{x}\left(\mathrm{x} \in\left(\mathrm{Q}_{<\mathrm{e},<\mathrm{e}, \mathrm{t}>>} \cap \mathrm{P}_{<\mathrm{e},<\mathrm{e}, \mathrm{t}>>}\right)\right) \Rightarrow \lambda \mathrm{P} \lambda \mathrm{Q}\left(\mathrm{Q} \cap \mathrm{P}^{-1}\right)$

matchmaking

if $\mathrm{P}$ is a relation from set $\mathrm{X}$ to set $\mathrm{Y}, \mathrm{P}^{-1}=\{<\mathrm{y}, \mathrm{X}>\in \mathrm{Y} \times \mathrm{X} \mid$ $<\mathrm{x}, \mathrm{y}>\in \mathrm{P}\}$

Example (35b) exploits the semantics of relational nouns to create matching pairs in a similar way as (33) does for non-relational nouns. After the matchmaking step, we can move to the intersection of two-place predicates, and mapping to individuals as with the bare coordination in (34). The semantics of (35) is spelled out in (36):

(36) Charles went to a wedding. Bride and groom looked happy.
a. $\quad \lambda \mathrm{P} \lambda \mathrm{Q}\left(\mathrm{Q}_{<\mathrm{e},<\mathrm{e}, \mathrm{t}>>} \cap \mathrm{P}_{<\mathrm{e},<\mathrm{e}, \mathrm{t}>>}^{-1}\right)($ bride $)($ groom)
b. $\quad$ BRIDE $\cap \mathrm{GROOM}^{-1}=\operatorname{BRIDE} \times \operatorname{GROOM}^{-1}=\{<x, y>\mid \operatorname{Bride}(\mathrm{x}, \mathrm{y}) \&$
$\operatorname{Groom}(\mathrm{y}, \mathrm{x})\}$
c. $\operatorname{RtoI}\left(\mathrm{BRIDE} \times \mathrm{GROOM}^{-1}\right)=\left\{\mathrm{x} \oplus \mathrm{y}: \mathrm{BRIDE} \times \operatorname{GROOM}^{-1}(\mathrm{x}, \mathrm{y})\right\}$
d. $\quad \iota \mathrm{x} \oplus \mathrm{y}\left(\mathrm{BRIDE} \times \mathrm{GROOM}^{-1}(\mathrm{x}, \mathrm{y})\right)$
e. $\operatorname{Happy}_{\mathrm{D}}\left(\iota \mathrm{x} \oplus \mathrm{y}\left(\mathrm{BRIDE} \times \mathrm{GROOM}^{-1}(\mathrm{x}, \mathrm{y})\right)\right)$

Example (36a) defines the intersection between two matching relational nouns, and (36b) takes their intersection, leading to the product of BRIDE and the inverse relation GROOM $^{-1}$, defining the set of couples getting married to each other. This product set is mapped to the set of plural individuals in the matching relation in (36c). In the context of a particular wedding, only a definite interpretation is possible, because there is only a single wedding couple (36d). The predicate happy applies to the unique wedding couple getting married to each other in the context of the wedding Charles went to.

Summarizing, we propose that and is polysemous between regular set intersection ( and $\left._{\text {joint }}\right)$ and set intersection ( $a n d_{\text {split }}$ ) enriched with a matchmaking function and the function RtoI. Both types of and take predicates as input and yield predicates as output, so both are appropriate for the conjunction of nouns and verbs.

This paper is not concerned with possible restrictions on split readings for verbs, but as far as split readings with coordinated nouns are concerned, we take the enriched meaning of product formation to correlate with 'natural coordination'. Natural coordination is the realm of lexical semantics and pragmatics, but can be viewed as falling 
out of the matchmaking semantics, as we will see in Sect. 4. Covert type-shifting is the hallmark of $N \& N$ constructions, which are fully discourse referential (with plural reference), but do not come with an overt article on the coordinate phrase. We will elaborate the syntax of bare coordination as lacking a DP projection in Sect. 5, and extend the analysis to DN\&N constructions in Sect. 6.

\section{The lexical semantics and pragmatics of the N\&N construction}

In this section we discuss the restriction of split coordination to 'natural' coordination (Sect. 4.1) and the special status of relational nouns (Sect. 4.2).

\subsection{Natural coordination and matchmaking}

In the literature, it hasn't gone unnoticed that not all bare coordinations are equally felicitous. The nature of the restrictions has been an important theme in the literature on coordination (Haiman 1983; Lambrecht 1984; Wälchli 2005; Dalrymple and Nikolaeva 2006; Märzhäuser 2013). So far, we have focused on well-formed N\&N constructions, but here are some examples of N\&N constructions that seem infelicitous, at least out of context:
a. ?? fork and handkerchief
b. ?? window and garden
c. ?? bride and dog

In our account, the infelicity of the coordinations in (37) receives a natural place at the level of the matchmaking semantics of $a n d_{\text {split }}$. More specifically, we propose that the domain that is used to generate possible matches is lexically and pragmatically constrained in much the same way as we generally constrain domains of quantification. When talking about a wedding, one can easily match the bride with the groom or the best man but chances are quite low that one would match the bride with some dog.

Lexical analyses account for the most frequent combinations of nouns in a natural coordination in terms of frames (cf. Haiman 1983; Lambrecht 1984; Wälchli 2005). So the most obvious interpretation of goblet and spoon is that they refer to the same table setting, where world knowledge concerning table setting grounds the lexical frame. However, as emphasized by Heycock and Zamparelli (2003), N\&N constructions are fully productive; that is, we cannot provide an exhaustive list of idiomatic matchmaking relations. So we need to account for these constructions in the grammar, rather than the lexicon.

We conclude that natural coordination ultimately resides in the pragmatic component of language, rather than in the lexical semantics. This account predicts that coordinations that are infelicitous out of the blue make perfect sense if we create a context in which both referents play a protagonist role in the event, as Lambrecht (1984:789) points out in relation to the German example (38). This creative use is also attested in the English and Dutch examples in (39) and (40): 
(38) Er ging in den Laden, um ein Hemd und ein Messer zu kaufen. Er fand, was er brauchte, und nachdem er Hemd und Messer bezahlt hatte, verließ er zufrieden den Laden.

[German]

'He went into the store to buy a shirt and a knife. He found what he needed, and after he paid for shirt and knife, he left the store content.'

Here are some custom bridal shower invitations that can show off the bride's dog. Bride and dog can be customized!

De Wisent-Europees oerrund, bruin, groot en gevaarlijk—staat stil tegen de Limburgse heuvel. Harrie Huijben staat tegenover het machtige rund met een appeltje in zijn uitgestrekte arm. 'Zit!' beveelt hij. Man en rund kijken elkaar strak aan. 'Zit!' klinkt het weer door de Limburgse heuvels.

'The bison-European ox, brown, large and dangerous — stops against the Limburg hill. Harrie Huijben is standing in front of the powerful ox holding an apple in his outstretched hand. 'Sit!' he orders. Man and ox just look at each other. 'Sit!' it sounds again through the Limburg hills.'

If the relation between people and their pets is so strong that the bride wants her dog to be involved in her wedding, bride and dog gets a natural coordination reading, as in (39). Similarly, in (40), the contextual frame for man and $o x$ is created by the meeting of the two in the previous discourse. In (38) the contextual frame is set up even more loosely as two objects on a shopping list.

\subsection{A lexical constraint on reciprocal conjunction}

Bare coordination with relational nouns generally leads to a reciprocal reading, as in (35)/(36) above. According to Staroverov (2007), reciprocal interpretations arise with relational nouns that constitute each other's inverse under the condition that presuppositions are preserved. Gender information is treated as presuppositional, so bride and groom are inverse relations that only differ in gender. Formally, Staroverov (2007) borrows the definition of Strawson entailment from von Fintel (1999) in (41a). He formulates the lexical constraint on relational nouns in reciprocal conjunction in (41b):

(41) a. A Strawson-entails B iff the conjunction of A and the presupposition of B entails B, written as: $\mathrm{A} \rightarrow{ }_{\mathrm{S}} \mathrm{B}$.

b. Two relations $\mathrm{R}_{1}$ and $\mathrm{R}_{2}$ allow for reciprocal conjunction iff they are Strawson-inverses, that is $\forall \mathrm{x} \forall \mathrm{y}$ if $\mathrm{R}_{1}(\mathrm{x}, \mathrm{y}) \rightarrow_{\mathrm{s}} \mathrm{R}_{2}(\mathrm{y}, \mathrm{x})$.

The constraint on reciprocal conjunction of relational nouns constitutes a stronger restriction on bare coordination than the instances of natural coordination discussed in Sect. 4.1, because it squarely resides in the lexicon.

Reciprocal readings arising with relational nouns that denote (Strawson) inverse relations constitute the strictest possible version of the matchmaking relation. However, a reciprocal interpretation is not strictly enforced, as already pointed out in relation to the DN\&N construction in (2e), as the context may override the preferred interpretation. Example (39) illustrates that relational nouns are not restricted to reciprocal readings, but also appear in other instances of bare coordination when conjoined with 
a non-relational noun. Coordination of relational nouns that are not Strawson inverses can still give rise to enriched interpretations, as the example in (42) shows:

Son and daughter are both liable for the expenses of the mother's burial.

Although the relational nouns in the two bare coordinate phrases are not inverse relations, the son and daughter in this example are the children of one and the same mother. This creates a different interdependency from the reciprocal conjunctions, but nevertheless the matchmaking semantics crucially builds on a two-place relation.

With relational nouns, the lexicon clearly plays a central role, but pragmatic considerations remain relevant. With non-relational nouns, the two-place relations are constructed by the matchmaking analysis, which allows more room for partly lexical, partly conceptual and pragmatic considerations.

\section{The syntax of the $N \& N$ construction}

Section 1 establishes a descriptive distinction between N\&N and DN\&N constructions. Given the absence of an overt article in N\&N constructions, we propose that a DP layer is simply missing for coordinate phrases. The account of this syntactic structure is embedded in the OT analysis that builds on the typology of number and article use developed by de Swart and Zwarts (2008, 2010).

\subsection{No DP layer above split coordination}

There is a crucial syntactic difference between joint and split cases of coordination in the availability of determiners that range over the coordination as a whole. For the joint reading of a friend and colleague of mine, we posited the syntactic structure in (43a), and the semantics in (43b) (cf. (31) above).

$$
\begin{aligned}
& \text { a. [DP a [CoordP friend } \text { and }_{\text {joint }} \text { colleague]] } \\
& \text { b. } \lambda \mathrm{Q} \exists \mathrm{x}(\mathrm{x} \in(\text { FRIEND } \cap \text { COLLEAGUE }) \wedge \mathrm{Q}(\mathrm{x}))
\end{aligned}
$$

The indefinite article $a$ lives in a D position situated above the joint coordinate phrase in $(43 a){ }^{8}$

For the split readings of N\&N, the claim that there is no DP layer above the coordinate phrase correlates with the ungrammaticality of plural articles when followed by two coordinated singular nouns. The English example in (44a) is from King and Dalrymple (2004), the judgment on the Spanish example in (44b) by Demonte and Pérez-Jiménez (2012) is grounded in data from the CREA corpus, and our own judgment on the French example (44c) is based on a corpus search carried out on Yahoo.fr in November, 2010: ${ }^{9}$

\footnotetext{
${ }^{8}$ We will posit a different syntactic structure for the split reading of (43a) as a DN\&N construction, see Sect. 6 below.

${ }^{9}$ Christina Märzhäuser (p.c.) notes that constructions like the one in (44c) are not completely out in French. One finds occurrences like (i) and (ii), for example:
} 
(44) a. *These boy and girl are eating a pizza.

b. $\{\mathrm{El} / * \mathrm{Los}\}$ abdomen $\mathrm{y}$ pecho aparecen relativamente

the $_{\mathrm{m} . \mathrm{sg}} / *$ the $_{\mathrm{m} . \mathrm{pl}}$ abdomen $_{\mathrm{m} . \mathrm{sg}}$ and chest $\mathrm{m}_{\mathrm{mg}}$ appear $_{\mathrm{pl}}$ relatively

abultados.

swollen $_{\text {m.pl }}$

'The abdomen and chest look relatively swollen.'

c. *Les homme et femme sont venus.

The $_{\mathrm{pl}}$ man and woman have come

Under the enriched analysis of conjunction developed in Sect. 3, a coordinate structure that gets a split interpretation is semantically plural. In line with their semantics, split coordination structures trigger plural agreement on the verb, so we might expect them to be headed by a plural article. The fact that-pace the marginal corpus examples signaled in footnote 10-plural articles are ungrammatical in English, Spanish, and French, as illustrated in (44) is a strong empirical argument against an analysis which projects a DP structure on top of the coordination of NPs, such as the one developed by Heycock and Zamparelli (2003). In line with Roodenburg's (2004, 2005) proposals, we take $\mathrm{N} \& \mathrm{~N}$ constructions to involve bare plurals. ${ }^{10}$ The bidirectional OT analysis developed in Sect. 5.3 provides a formal account, which is embedded in the typology of number and article use developed by de Swart and Zwarts (2008, 2010), summarized in Sect. 5.2.

\subsection{An OT typology of number and article use}

The syntactic constraint that accounts for the bareness of N\&N constructions is inspired by the typology de Swart and Zwarts $(2008,2010)$ develop in Optimality The-

(i) mes frère et soeur

[French]

myPL brother and sister

(ii) les date et signature

the $_{\mathrm{PL}}$ date and signature

We note that these cases are extremely rare and take them to be outliers that are to be explained by the sloppy writing style of blogs (for (i)) or an unnatural bureaucratic writing style (for (ii)). Support for these explanations mainly comes from languages like Russian that—unlike French-productively allow for these constructions (see also Sect. 5.4).

An anonymous reviewer points out that Spanish allows coordination of proper names with a plural article if an adjective is involved, as in (iii) (from Demonte and Pérez-Jiménez 2012):

$$
\begin{aligned}
& \text {... a no ser que cerca anden los temibles } \quad \text { Capirucho y Capirote... } \\
& \text { unless near walk.PRS.SBJU.3PL the.M.PL fearsome.PL Capirucho and Capirote } \\
& \text {... unless the fearsome Capirucho and Capirote are around...' }
\end{aligned}
$$

The construction with the adjective + article is also found outside of coordination contexts (e.g. the terrible $M r . C$.). Whatever the internal structure of this configuration, the special features of proper names lead us to think that los temibles Capirucho y Capirote is not an instance of the DN\&N construction. Consequently, it falls outside the scope of our investigation. We don't see how the CCA analysis would fare better at accounting for these cases than ours, given that los clearly doesn't agree with Capirucho.

${ }^{10}$ As an anonymous reviewer points out, the lack of a DP projection on N\&N constructions potentially has important implications for syntactic theory, in particular when it comes to the status of Person and Case as nominal features or features of $\mathrm{D}$. This discussion leads us outside the scope of our paper. 
ory (OT). This typology is concerned with the syntactic shape of nominals that occur in regular argument position. They propose a general markedness constraint that blocks functional structure in the nominal domain (*FunctN, 45a). Furthermore, they propose three faithfulness constraints governing the expression of number and articles as in (45b-d):

a. *FunctN: avoid functional structure in the nominal domain

b. FPl: reference to a plurality of individuals must be reflected in the form

c. FDr: the presence of a discourse referent in the semantics corresponds with an expression that carries discourse referential force

d. FDef: reference to discourse unique individuals requires the use of an expression of definiteness

The rationale behind the faithfulness constraints in $(45 b-d)$ is that semantic concepts should have syntactic correlates. Singular/plural contrasts should involve a number projection, discourse referents require a determiner projection and uniqueness or familiarity an expression of definiteness. ${ }^{11}$ This is of course not the whole story: if it were, we would always expect a perfect parallel between syntax and semantics; i.e., all languages would grammaticalize plural markers as well as indefinite and definite articles. Typological variation comes from the interaction of the faithfulness constraints (45b-d) with the markedness constraint in (45a) in terms of the weight assigned to each constraint.

The markedness constraint * FunctN bars a strict mapping from semantics to syntax and leads to underspecified forms. ${ }^{12}$ If $*$ FunctN is ranked above the faithfulness constraints FPl, FDr and FDef, we expect nouns to be neutral with respect to number, argument-hood and definiteness. This is-broadly speaking - the case for Mandarin Chinese nouns, as illustrated in (46):

a. Wŏ kànjiàn xióng le.

[Mandarin Chinese]

I see bear ASP

'I saw a bear. / I saw the bear. / I saw bears. / I saw the bears.'

b. Shì xióng.

is bear

'He's a bear. / They are bears. / He's the bear. / They are the bears.'

In Mandarin Chinese a bare noun like xiong will—depending on the syntactic, semantic and pragmatic context-receive a singular or plural, definite or indefinite, and argumental or predicational interpretation (e.g. Kuo 2008).

English is at the other end of the spectrum, because it grammaticalizes a singular/plural contrast as well as definite and indefinite articles, so it exemplifies the ranking $\{$ Fpl, FDef, FDr $\}>$ *FunctN. As a result of the high ranking of FDr, English

\footnotetext{
${ }^{11}$ Note that we don't take position here in the discussion about whether or not definite expressions have their own projection (for discussion see a.o. Zamparelli 2005; Borer 2005, and de Swart and Zwarts 2010). The formulation of FPl is a bit more general than the one in de Swart and Zwarts (2008), which focused primarily on plural morphology on the noun.

${ }^{12}$ Note that the OT system focuses on number projection and article use. Accordingly, *FunctN does not target quantifiers, numerals or even demonstratives, which come with lexical information beyond discourse referential force.
} 
Fig. 1 English bare plurals are indefinite under bidirectional OT bare plural

definite plural
Max

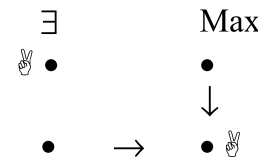

blocks bare singulars from regular argument position. Other rankings of the constraints have been argued by de Swart and Zwarts $(2008,2010)$ to account for the use of bare nouns cross-linguistically, so each constraint is independently motivated.

The OT typology feeds back into the semantics by means of bidirectional Optimality Theory (see Hendriks et al. 2010 for an introduction into bidirectional Optimality Theory as a model of the syntax-semantics interface). In English for instance, the overt realization of a definite article blocks the definite interpretation of the bare plural, as illustrated in Fig. 1.

Figure 1 evaluates the possible combinations of definite and bare plurals with existential or definite interpretations. The arrows indicate preference relations. As part of its inherent semantics, the plural definite article imposes unique (maximal) reference and/or discourse familiarity, so Max is preferred over $\exists$. Because of the high ranking of FDef in English, an overt expression of maximality is required, so the definite plural is preferred over the bare form when conveying the meaning Max. The two arrows pointing to <def,Max $>$ characterize the definite plural with a maximal interpretation as an optimal form-meaning pair. Given the bidirectional grammar, both <def, $\exists>$ and $<$ bare,Max $>$ are suboptimal form-meaning pairs. This leaves the pair $<$ bare, $\exists>$ as the form-meaning pair that has no arrows pointing towards it or away from it. The bare plural thus qualifies as an 'elsewhere' form that takes up the meaning $\exists$ not grammaticalized by means of the definite article. Bi-directional OT thus offers a theory of blocking in the sense of Chierchia (1998) and is reminiscent of Kiparsky's (1973) and Halle and Marantz's (1993) use of the elsewhere condition.

In terms of Partee's (1987) theory of type-shifting, the grammar of English overtly encodes the iota shift (or maximality operator, by means of the plural definite article), but covertly allows the existential shift with the bare plural. Mandarin Chinese covertly allows both the iota shift and the existential shift, because there is no grammatical marker of definiteness in the language, so there is no distribution of meaning over different forms as in the English pattern in Fig. 1. Accordingly, the bare noun in (46a) and (b) is compatible with both the existential $(\exists)$ and the definite ( $\iota$ or Max) interpretation. Along these lines, the bidirectional OT analysis accounts for Partee's and Chierchia's insight that universal semantic shifts apply freely unless they have an overt realization. As we will see in Sect. 5.3, this insight underlies the freedom in interpretation of $\mathrm{N} \& \mathrm{~N}$ constructions. Instances of cross-linguistic variation with split conjunction have been observed in the literature, and are accounted for by means of reranking of OT constraints in Sect. 5.4.

\subsection{N\&N constructions in bidirectional OT}

The OT grammar outlined in Sect. 5.2 can account for the observation that languages like English and French tolerate N\&N constructions with a split interpretation, but not a joint interpretation (cf. (6)). Indeed, split coordination phrases are semantically 
plural (cf. Roodenburg 2005), and the connective and satisfies the highly ranked FPl, as is visible also in the plural agreement on the verb. The plural semantics of split coordination introduces a plural discourse referent through the back door of presupposition accommodation, as outlined in Farkas and de Swart (2003) for bare plurals. As argued by de Swart and Zwarts (2008, 2010), presupposition accommodation is sufficient to satisfy Fdr, and thereby licenses argument-hood of the coordinated bare singular.

This cannot be the whole story though. Indeed, if we were to stop here, the OT grammar developed in Sect. 5.2 would predict that only existential readings are available for split coordinations, and projection of a definite article would be required to obtain a definite reading. In reality, no definite or indefinite articles can be projected on top of a split coordination (cf. Sect. 5.1). In this section, we will enrich the OT grammar developed in Sect. 5.2 in such a way that it accounts for the fact that DP projections are illicit on top of split coordinations in French and English. This derives both a definite and an indefinite interpretation for $\mathrm{N} \& \mathrm{~N}$ constructions.

In order to formalize the difference in behavior between joint and split conjunction, we make two assumptions. The first is that there are two types of and, connected through our polysemous semantics. And joint gives rise to joint coordinations (JCo-

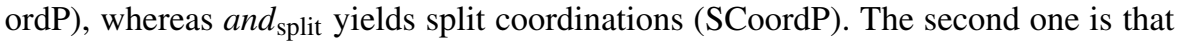
the matchmaking semantics of split conjunction correlates with this specific syntactic restriction against DP projections on top of CoordP. Accordingly, we posit a subconstraint of the general markedness constraint *FunctN which we label *FunctNSCoordP in (47a), and which targets split coordinate structures. For English, Dutch, Spanish, and French, we assume the ranking in (47b):
a. *FunctNSCoordP: Avoid functional structure on top of a split coordi- nation
b. $\{$ FPl, *FunctSCoordP $\}>\{$ FDr, FDef $\}>>$ FunctN.

*FunctNSCoordP is a contextual markedness constraint, i.e., a construction-specific subconstraint of the general markedness constraint *FunctN. If ranked above a relevant faithfulness constraint which itself outranks the general markedness constraint, a contextual markedness constraint captures an exception to the general rule enforced by the faithfulness constraint. If the contextual markedness constraint is ranked at the same level or below the general markedness constraint, it is harmonically bound to the general markedness constraint, and has no independent effect. In the case at hand, the ranking of the markedness constraint *FunctSCoordP above the faithfulness constraint FDr and FDef implies that split coordination lifts the normal requirement on definite and indefinite article use.

In the phonological OT literature, is has been debated whether exceptions to a general rule should be handled by contextual markedness constraints, or positional faithfulness constraints (cf. Kager 1999). For instance, the devoicing of voiced consonants in coda position in languages like Dutch and German can be treated in terms of a contextual markedness constraint such as *VoicedCoda (avoid voicing distinctions in coda position, e.g. Kager 1999) or a positional faithfulness constraint such as IDOnsLar (consonants in onset position should be faithful to underlying laryngeal specification, Lombardi 1999). In the choice between one or the other approach, 
much depends on whether the contrast induced by the faithfulness constraint targets a particular position (against all other positions), or whether the lack of marking relates to a particular context (against all other contexts). Lombardi argues that voicing distinctions are also obliterated in positions in between the onset and the coda, which supports the positional faithfulness account. Kager (1999) argues that functional considerations may also favour positional faithfulness: contrasts are best realized in perceptually salient positions, such as the onset of a word. Interaction with a third constraint may also help to determine the issue. After weighing all options, Kager concludes that both contextual markedness and positional faithfulness are needed in OT for a full factorial typology.

As far as the system of article use is concerned, we think that it makes more sense to characterize coordinate constructions as exceptions, because of their higher level of complexity. This makes it less likely that faithfulness constraints specifically target N-headed nominal structures, and favours a contextual markedness constraint that obliterates distinctions in that complex coordinate structure. Note further that in our system, three faithfulness constraints are competing with the general markedness constraint *FunctN. The formulation of three construction-specific faithfulness constraints would make the system a lot heavier than the formulation of one contextual markedness constraint. Such a proliferation of faithfulness constraints would leave open the theoretical possibility that definite and indefinite articles (driven by contextualized FDef and Fdr respectively) interact with coordination in different ways. We are not aware of any language in which this happens. We conclude that an account of article choice in coordinate structures formulated in terms of contextual markedness faces less empirical problems, is more economical, and has a higher explanatory value than an account in terms of contextual faithfulness.

Crucially, the ranking in (47b) blocks projection of a DP above the split coordination, so articles are ruled out, as desired in view of the examples in (44). As a consequence, both the existential shift and the iota shift become available covertly for N\&N constructions, which therefore acquire both definite and existential interpretations as illustrated in Sect. 2 above. The range of interpretations of the N\&N construction is thus similar to the range of interpretations of bare nominals in a language like Mandarin Chinese, in the absence of an article system in this language (cf. (46)). A proper investigation of the contextual preference for a definite or indefinite interpretation of an N\&N construction is outside the scope of this paper, but we expect similar considerations of syntactic configuration, lexical semantics, and pragmatic reasoning to play a role.

\subsection{Cross-linguistic variation in article use with split and joint coordination readings}

The ranking we posit here for English, Dutch, French, and Spanish applies to a wide range of languages, but is not universal. In line with general principles of OT, we expect the constraint *FunctNSCoordP to be subject to reranking. Crucial for us is that it interacts with the more general markedness constraint *FunctN. We show this on the basis of a comparison between two types of languages. The first is one in which *FunctN is ranked low with respect to the faithfulness constraints governing article use and *FunctNSCoordP is ranked high. In this type of language we expect Split Coordination Phrases to behave differently from Joint Coordination Phrases and 
standard arguments in allowing for bare nominals. Examples of this type of language are the languages we have treated up till now: English, Dutch, Spanish, and French. The second type of language is one in which *FunctN is ranked high with respect to the faithfulness constraints governing article use, thus rendering *FunctNSCoordP obsolete. In this type of language we expect Split Coordination Phrases to behave in the same way as Joint Coordination Phrases and standard arguments in allowing for bare nominals. Mandarin Chinese and Russian exemplify this type of language. In (48) and (49) we show that coordination phrases involving bare nominals in Mandarin Chinese and Russian allow both for a split and a joint reading:

Nàtiān yĭhòu tā yŏu le gēge hé péngyou

[Mandarin Chinese] that.day after he has ASP brother and friend

(i) 'After that day he had a person who was both a friend and a brother.'

(ii) 'After that day he had (found back) the (his) brother and the (his) friend.'

Na vstreču prišel drug i kollega
to meeting come.PST.SG.MASC friend.NOM and colleague.NOM
Maši.
Maša.GEN
'A friend and colleague of Mary's came to the meeting.'

[Russian]

Maša.GEN

The fact that Mandarin Chinese does not require an article for bare nouns carries over to bare coordination constructions. Accordingly, the bare coordinate structure in (48) can set up a singular discourse referent that has the properties denoted by the two nouns under the joint interpretation of conjunction. Similar observations can be made for Russian (49). Unlike its English counterpart, the N\&N construction drug i kollega allows for a joint reading. This is made explicit in (49) by the singular agreement on the verb.

Russian is interesting in another respect: it is one of the typologically rare languages that allow for a plural determiner to precede a coordination of two singular nouns. We illustrate on the basis of (50) and (51).

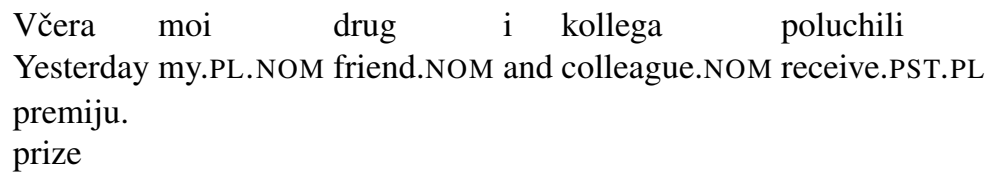

èti mužčina i ženščina
these man and woman

(King and Dalrymple 2004)

Moi and èti are plural despite the fact that the coordinated nouns that follow them are singular. We consider this to be strong evidence in favour of the hypothesis that they range over the whole SCoordP. The fact that there are languages that allow this is a crucial piece in the puzzle we are addressing in the next section. In contrast to èti in (51), we claim that this in examples like (52) does not range over the coordination as a whole:

This man and woman are in love. 
The reasoning that underlies our claim is that if this were to range over the coordination as a whole, we would expect it to be plural (cf. (50), (51)). This claim has been challenged in the literature, in which it has become standard to assume that this ranges over the coordination as a whole but gets its singularity through an agreement procedure known as Closest Conjunct Agreement (CCA). Russian however shows that CCA is not necessary and raises the question whether the contrast between Russian and English type languages really resides in a difference in agreement, or rather in a difference between the presence or absence of a D projection on top of SCoordPs. In Sect. 6 we will assume the latter option, and argue that Ds that precede SCoordPs in English-type languages only range over the first conjunct. What makes this option attractive is that we don't have to come up with two sets of number features for man and woman: the coordination as a whole is plural and takes care of the agreement on the verb but the first conjunct is singular and this is what takes care of the agreement on the D.

\section{The DN\&N construction: syntax and semantics}

In this section, we extend the analysis developed for $N \& N$ coordination in Sects. 3-5 to $\mathrm{DN} \& \mathrm{~N}$ coordination. $\mathrm{DN} \& \mathrm{~N}$ is the label we propose for coordination constructions that have a determiner on the first conjunct, but not on the second. Examples are in (53) ((a) and (b) from Heycock and Zamparelli 2005; (c) from Demonte et al. 2011; (d) from Arnold et al. 2006):

a. This man and woman are in love.

b. Deze man en vrouw zijn gescheiden.

[Dutch]

This man and woman are divorced.

c. El abdomen y pecho aparecen relativamente the $_{\mathrm{m} . \mathrm{sg} / * \mathrm{~m} . \mathrm{pl}}$ abdomen $_{\mathrm{m} . \mathrm{sg}}$ and chest $\mathrm{m}_{\mathrm{mg}}$ appear $_{\mathrm{pl}}$ relatively abultados.

[Spanish] swollen

'The abdomen and chest look relatively swollen.'

d. $\mathrm{O}$ presidente e amigo comeram juntos. [Portuguese] the $_{\text {sg.m }}$ president $_{\text {sg.m }}$ and friend $d_{\text {sg.m }}$ ate $e_{\mathrm{pl}}$ together

'The president and (his) friend ate together.'

We address the syntax and semantics of such coordination constructions, and account for their agreement patterns in three steps. ${ }^{13}$ First, we determine the syntax of DN\&N

\footnotetext{
${ }^{13}$ We refrain from discussing quantificational versions of DN\&N constructions such as every boy and girl or most men and women. These constructions do not present a morpho-syntactic problem as there are no mismatches in verbal agreement. Their semantics can be handled in the generalized conjunction framework by a raised type of the common noun, as pointed out by Cooper (1979) (discussed in Partee and Rooth 1983), where they give rise to the interpretation 'every boy and every girl' and 'most men and most women' respectively. As Heycock and Zamparelli (2005) argue, this approach does not generalize to all DN\&N constructions, and it obviously does not explain the matchmaking effects. Note also that DN\&N constructions are severely restricted in French (cf. the discussion of example (67) below), while quantificational versions seem to be tolerated more freely, thus confirming the difference in status of the
} 
constructions (Sect. 6.1), then we set up a semantics of DN\&N constructions which builds on the matchmaking semantics of conjunction we developed for bare coordination (Sect. 6.2). Finally, we address some issues that our account raises for adjectival agreement (Sect. 6.3).

\subsection{Morpho-syntax: mismatches in agreement}

The DN\&N constructions in (53) have drawn quite a bit of attention in the syntactic literature, because they display mismatching agreement: the determiner on the first noun is singular, but verbal agreement is plural. According to King and Dalrymple (2004), the singular form of the determiner is licensed by distribution down to each conjunct, because examples like (54a) and (b) are ungrammatical. Arnold et al. (2006) and Demonte and Pérez-Jiménez (2012) show that the configuration in (53) must be an instance of closest conjunct agreement, because the determiner always agrees in number and gender with the first conjunct. The Portuguese example in (2d), the corpus-based Spanish examples in (2c) and (54c), and the Catalan and English examples in (54d) and (e) support their view:
a. *These boy and girl.
b. *These boys and girl.
c. Sus pómulos y nariz aparecían afilados. his $_{\mathrm{pl}}$ cheeks $_{\mathrm{m} . \mathrm{pl}}$ and nose $_{\text {f.sg }}$ seemed $_{\mathrm{pl}}$ sharp $_{\mathrm{m} . \mathrm{pl}}$ 'His cheeks and nose looked sharp.'
d. Els treballs han de consignar el nom i

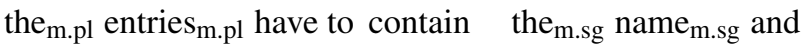 cognoms de l'autor. surnames $_{\text {m.pl }}$ of the m.sg $_{\text {author }}$ 'Entries must contain the name and surnames of the author.' [Catalan]
e. Just recently, my son's skin around his eyes and nose turned lighter than the rest of his face.

With Arnold et al. (2006) and Demonte and Pérez-Jiménez (2012), we therefore assume that DN\&N constructions involve closest conjunct agreement, rather than distributive singular agreement. While the construction in (54a) is ruled out by the grammar developed in Sect. 5, the ill-formedness of (54b) is most likely due to the lack of a natural coordination reading. Section 4 gave examples of $N \& N$ constructions that can be saved by the context in which they appear. Along similar lines, we provide attested examples of $\mathrm{D}_{\mathrm{pl}} \mathrm{N}_{\mathrm{pl}} \& \mathrm{~N}_{\mathrm{sg}}$ constructions in (55):

(55) a. You'd all die of laughter if you saw what my sister, my assistant and I were all doing to get these boys (and dog!) to look our way and smile!

b. These children and mother were living on charity of good people.

Note that these examples clearly involve the matchmaking semantics: the boys and the dog in (56a) are somehow part of a group, and the coordination in (55b) must

two constructions. The quantificational versions do not affect the argumentation in Sect. 5, as quantifiers and articles are subject to different optimality-theoretic constraints (cf. de Swart and Zwarts 2010 for discussion of this point). 
be read as 'these children and their mother'. In view of the felicitous examples in (55), we claim that the asterisk King and Dalrymple (2004) put on (54b) should be weakened to pragmatic infelicity.

The mismatching agreement pattern in (54) and (55) constitutes a challenge for the syntax-semantics interface. On the one hand, we need to posit plural reference for the coordinated structure as a whole, which clearly accounts for plural verbal agreement. On the other hand, we need to block the plural determiner in (54a) (cf. also (44)), and account for agreement of the determiner with the first conjunct, rather than the coordinate structure as a whole. The literature presents several solutions to this problem (King and Dalrymple 2004; Heycock and Zamparelli 2005; Arnold et al. 2006; Demonte et al. 2011). What these analyses have in common is that they all rely on a version of the syntactic structure in (56); that is, they all posit a DP structure on top of the coordinate phrase: ${ }^{14}$

$$
\text { [DP } \left.\mathrm{D}_{\text {sg }}\left[\text { CoordP } \mathrm{NP}_{\text {sg }} \text { and } \mathrm{NP}_{\text {sg }}\right]\right]
$$

The structure in (56) is incompatible with the claims made in Sect. 5 above about $\mathrm{N} \& \mathrm{~N}$ constructions. Obviously, we can hardly claim that $\mathrm{N} \& \mathrm{~N}$ constructions forbid projection of a DP, yet follow the literature that puts forward the syntactic structure of DN\&N constructions in (56). There are two ways out of this dilemma: either we give up the analysis of $N \& N$ constructions as bare plurals, or we provide a different account of the DN\&N constructions. We do not want to give up our analysis of the $\mathrm{N} \& \mathrm{~N}$ construction so easily. Accordingly, this section explores the feasibility of an account of the DN\&N construction that does not rely on the structure in (56).

The first step is to consider an alternative analysis which relies on coordination of DPs with an elided D on the second conjunct, as in (57) (Camacho 2003; Chaves 2008):

$$
\text { [CoordP [DP D NP] and [DP } \varnothing \mathrm{NP}]]
$$

Demonte et al. (2011) reject the ellipsis analysis, and claim that it makes the wrong empirical predictions. For us, (57) is an unattractive proposal, because it posits an empty D, while an important aim of the OT analysis developed in Sect. 5 above is to avoid positing projections that do not contain overt material. So let us agree with Demonte et al. that (57) is not the alternative we are looking for. However, the attractive feature of (57) is that it accounts for closest conjunct agreement by taking the overt $\mathrm{D}$ to be in construction with the first conjunct. We exploit this idea in the structure (58) we explore as an alternative to (56) and (57):

$$
\text { [CoordP [DP D NP] and [NP NP]] }
$$

The advantage of (58) is that we don't need to motivate null elements as in (57), nor do we need to assume two sets of agreement features as Demonte et al. do in relation to (56). This doesn't mean we reject the use of null elements in general, or that we do not acknowledge instances of mixed agreement, but just that an analysis that doesn't

\footnotetext{
${ }^{14}$ Demonte et al. (2011) further argue that the internal structure of the coordinate phrase involves a structural asymmetry between the first and the second conjunct. We do not assume an asymmetric syntax, but rely on the dynamic semantics of conjunction to account for dependency relations (cf. Sect. 6.2).
} 
need such ingredients has the merit of simplicity. The configuration in (58) remains close to the surface structure, which allows us to deal with the agreement patterns at a local level. Consider the agreement patterns in examples like (59) (from Demonte and Pérez-Jiménez 2012):

$$
\begin{aligned}
& \text { La flora y relieve me sorprendieron mucho. } \\
& \text { the }_{\text {sg.f }} \text { flora }_{\text {sg.f }} \text { and relief } \text { sg.m }_{\text {me surprised }} \text { much } \\
& \text { [CoordP } \left.\left._{\text {[DP the }} \text { sg.f } \text { flora }_{\text {sg.f. }}\right] \text { and [NP } \text { relief }_{\text {sg.m }}\right] \text { [vP } \text { me surprised }_{\mathrm{pl}} \text { much] }
\end{aligned}
$$

Under the constituent structure in (59), the feminine singular article la is in construction with the first conjunct, which involves the singular feminine noun flora, so this immediately explains closest conjunct agreement. The coordination phrase as a whole has plural reference as a result of the semantics of split coordination, which triggers plural verb agreement on sorprendieron. Thus, under our analysis, there is in fact no mismatch in agreement features in DN\&N constructions. The natural account of agreement on D vs. agreement on the verb, combined with the surface level orientation of the constituent structure in (58), provides strong syntactic evidence in favour of an approach to DN\&N coordination in these terms.

The main problem the structure in (58) faces is that it clearly violates the assumption that conjuncts need to be alike in syntactic category and semantic type. This assumption motivates the generalized conjunction analysis of Partee and Rooth (1983), and underlies the subsequent literature on coordination (cf. Zamparelli 2011 for a recent statement). Now, the structure in (58) posits coordination of two expressions that do not belong to the same syntactic category, namely a DP and an NP. If we assume the type of a DP is type $<<e, t>, t>$, and assume that the type of an NP is type $<e, t>$, because NPs denote properties, we are dealing with two different semantic types as well.

The only way we can fix the mismatch in syntactic structure is by abandoning (58) in favour of either (56) or (57). In view of the problems these syntactic structures face, this route is blocked to us. Let us assume that a mismatch in syntactic category can be overcome by a semantics that treats the two expressions as conjoinable types (see Borsley 2005; Haspelmath 2007; Zamparelli 2011). Section 6.2 saves the structure of DN\&N constructions as posited in (58) by developing a semantics of DN\&N constructions that deals with the type mismatch by accommodation of a discourse referent for the second conjunct.

\subsection{A dynamic semantics for DN\&N constructions}

Intuitively, the semantics we want to develop for DN\&N constructions like $a$ man and woman is incremental in the sense that it relates the woman in the second conjunct to the man introduced by the indefinite in the first. The anaphoric dependency in an example like (60) illustrates this:

(60) Op het terras zaten een $\operatorname{man}_{\mathrm{i}}$ en duidelijk op hem $\mathrm{i}_{\mathrm{i}}$ verliefde vrouw. on the terrace sat.PL a $\operatorname{man}_{i}$ and clearly with him ${ }_{i}$ in.love woman

[Dutch]

'On the terrace, a man was sitting with a woman who was clearly in love with him.' 
The most likely interpretation of (60) is that of a couple in love. In order to ensure the anaphoric relation between the two conjuncts, we need a dynamic version of conjunction. Given that we need to provide an incremental analysis internal to the coordinate phrase, our analysis of conjunction needs to be more fine-grained than the one proposed by Kamp and Reyle (1993). Formally, our analysis adopts the version of DRT presented in van der Sandt and Geurts (1991) and van der Sandt (1992). The crucial difference with standard DRT is that DRSs are extended with an A-structure that takes care of presuppositional material. This new type of DRS is defined as follows:

DRS definition:

A DRS K is a triple $\langle\mathrm{U}(\mathrm{K}), \mathrm{Con}(\mathrm{K}), \mathrm{A}(\mathrm{K})\rangle$, where:

- $\mathrm{U}(\mathrm{K})$ is a set of discourse markers,

- Con $(\mathrm{K})$ is a set of DRS conditions,

- and $\mathrm{A}(\mathrm{K})$ is a (possibly empty) set of DRSs representing presupposed information.

In this set-up, we can define the incremental semantics of conjunction of DP and DP as in (62):

a man and a woman

a. [CoordP [DP a man] and [DP a woman]]

b. $\llbracket \mathrm{a} \operatorname{man} \rrbracket=\langle\{\mathrm{x}\},\{\operatorname{man}(\mathrm{x})\}, \varnothing\rangle_{\mathrm{K}}$

c. $\llbracket$ a man and $\rrbracket=\left\langle\{x, X\},\{\operatorname{man}(x), X=x \oplus y\},\left\{\langle\{y\}, \varnothing, \varnothing\rangle_{\mathrm{L}}\right\}\right\rangle_{\mathrm{K}}$

d. $\llbracket$ a man and a woman $\rrbracket=\langle\{\mathrm{x}, \mathrm{X}, \mathrm{z}\},\{\operatorname{man}(\mathrm{x}), \mathrm{X}=\mathrm{x} \oplus \mathrm{y}, \operatorname{woman}(\mathrm{z})$, $\left.\mathrm{z}=\mathrm{y}\},\left\{\langle\{\mathrm{y}\}, \varnothing, \varnothing\rangle_{\mathrm{L}}\right\}\right\rangle_{\mathrm{K}}$

e. $\quad$ a man and a woman $\rrbracket=\langle\{\mathrm{x}, \mathrm{X}, \mathrm{z}\},\{\operatorname{man}(\mathrm{x}), \mathrm{X}=\mathrm{x} \oplus \mathrm{z}, \operatorname{woman}(\mathrm{z})\}$, $\varnothing\rangle_{\mathrm{K}}$

The analysis of the DP a man is spelled out in (62b): it involves the introduction of a discourse referent $\mathbf{x}$ and the condition $\operatorname{man}(\mathbf{x})$. Example (62c) spells out the operations that the addition of and triggers. Inspired by the literature on coordination, we take the addition of and after a DP to trigger the presupposition that another discourse referential expression will follow. This is formally represented by the introduction of the discourse referent $y$ in the presuppositional structure of the DRS. The semantic contribution of and in $\operatorname{Con}(\mathrm{K})$ is sum formation of the respective discourse referents of its two conjuncts. This is represented by the introduction of the plural discourse referent $\mathbf{X}$ in $\mathrm{U}(\mathrm{K})$, and the condition $\mathbf{X}=\mathbf{x} \oplus \mathbf{y}$ in $\operatorname{Con}(\mathrm{K})$. In (62d), the contribution of $a$ woman is spelled out in the context of $a$ man and. It involves the addition of $\mathbf{z}$ to $\mathrm{U}(\mathrm{K})$, and the condition of $\operatorname{woman}(\mathbf{z})$ to $\operatorname{Con}(\mathrm{K})$. The incremental interpretation within the coordinate phrase involves a process of anaphora resolution that identifies the asserted discourse referent $\mathbf{z}$ as identical to the presupposed discourse referent $\mathbf{y}$. This process of presupposition binding leads to replacement of all occurrences of $\mathbf{y}$ by $\mathbf{z}$, and deletion of $\mathrm{A}(\mathrm{K})$ as in (62e). For DN\&N constructions, we use this incremental semantics of conjunction, enriched with matchmaking.

Under the general syntax of DN\&N constructions in (58) above, we obtain (63a) as the phrase structure of $a$ man and woman: 
(63) a man and woman in love with him

a. [CoordP [DP a man] and [NP woman]]

b. $\llbracket \mathrm{a} \operatorname{man} \rrbracket=\langle\{\mathrm{x}\},\{\operatorname{man}(\mathrm{x})\}, \varnothing\rangle_{\mathrm{K}}$

c. $\quad \llbracket$ a man and $\rrbracket=\left\langle\{x, X\},\{\operatorname{man}(x), X=x \oplus y\},\left\{\langle\{y\},\{R(y, x)\}, \varnothing\rangle_{\mathrm{L}}\right\}\right\rangle_{\mathrm{K}}$

d. $\quad$ a man and woman $\rrbracket=$ (matchmaking version of conjunction)

$\langle\{\mathrm{x}, \mathrm{X}\},\{\operatorname{man}(\mathrm{x}), \mathrm{X}=\mathrm{x} \oplus \mathrm{y}, \operatorname{woman}(\mathrm{z}), \mathrm{z}=\mathrm{y}\}$,

$\left.\left\{\langle\{\mathrm{y}, \mathrm{z}\},\{\mathrm{R}(\mathrm{y}, \mathrm{x})\}, \varnothing\rangle_{\mathrm{L}}\right\}\right\rangle_{\mathrm{K}}$

e. $\quad$ a man and woman in love with him $\rrbracket=$

$\langle\{\mathrm{x}, \mathrm{X}\},\{\operatorname{man}(\mathrm{x}), \mathrm{X}=\mathrm{x} \oplus \mathrm{y}, \operatorname{woman}(\mathrm{z}), \mathrm{z}=\mathrm{y}, \operatorname{Love}(\mathrm{z}, \mathrm{x})\}$,

$\left.\left\{\langle\{\mathrm{y}, \mathrm{z}\},\{\mathrm{R}(\mathrm{y}, \mathrm{x})\}, \varnothing\rangle_{\mathrm{L}}\right\}\right\rangle_{\mathrm{K}}$

f. $\quad$ a man and woman in love with him $\rrbracket=$

$\langle\{\mathrm{x}, \mathrm{X}, \mathrm{z}\},\{\operatorname{man}(\mathrm{x}), \mathrm{X}=\mathrm{x} \oplus \mathrm{z}, \operatorname{woman}(\mathrm{z}), \operatorname{Love}(\mathrm{z}, \mathrm{x})\}, \varnothing\rangle_{\mathrm{K}}$

(anaphora resolution and accommodation)

The analysis of the DP a man in (63b) is standard. Example (63c) spells out the operations that the addition of and triggers. A dependency relation $\mathbf{R}$ between $\mathbf{y}$ and $\mathbf{x}$ to $\mathrm{A}(\mathrm{K})$ adds the matchmaking step. In the absence of an overt article, no discourse referent is introduced in $\mathrm{U}(\mathrm{K})$ by the second conjunct woman, but (63d) adds the existence of a discourse referent $\mathbf{z}$ to $\mathrm{A}(\mathrm{K})$, and the condition $\operatorname{woman}(\mathbf{z})$ to $\operatorname{Con}(\mathrm{K})$. Furthermore, the incremental interpretation within the coordinate phrase triggers an anaphora resolution process that identifies $\mathbf{z}$ with $\mathbf{y}$. In example (60) the presupposed dependency relation $\mathbf{R}$ is bound to the asserted love relation, as in (63e).

The main difference between DN\&DN and DN\&N constructions is that $\mathbf{z}$ is an asserted discourse referent in $(62 \mathrm{~d})$ and resides in $\mathrm{U}(\mathrm{K})$, whereas it is a presupposed discourse referent in $(63 \mathrm{~d})$, and thus sits in $\mathrm{A}(\mathrm{K})$. The extra step required in DN\&N constructions is to allow accommodation of $\mathbf{z}$, which promotes this discourse referent to $\mathrm{U}(\mathrm{K})$, as in (63f). This accommodation process constitutes the dynamic semantic counterpart of the type-shift we are familiar with from N\&N constructions (cf. Sect. 3 above). In variants of the DN\&N constructions in which there is no overt indication of the value of $\mathbf{R}$, a contextually relevant relation will be accommodated.

The analysis extends in a straightforward way to DN\&N constructions involving relational nouns with a reciprocal interpretation. This is formally spelled out in (64):

A bride and groom

a. [CoordP [DP a bride] and [NP groom]]

b. $\llbracket$ a bride $\rrbracket=\left\langle\{\mathrm{x}\},\{\operatorname{bride}(\mathrm{x}, \mathrm{y})\},\left\{\langle\{\mathrm{y}\}, \varnothing, \varnothing\rangle_{\mathrm{L}}\right\}\right\rangle_{\mathrm{K}}$

c. $\llbracket$ a bride and $\rrbracket=\langle\{x, X\},\{\operatorname{bride}(x, y), X=x \oplus y\},\{\langle\{y\},\{R(y, x)\}$,

$\left.\left.\varnothing\rangle_{\mathrm{L}}\right\}\right\rangle_{\mathrm{K}}$

d. $\quad$ a bride and groom $\rrbracket=$

$\left\langle\{x, X\},\left\{\operatorname{bride}(x, y), X=x \oplus y, \operatorname{groom}^{-1}(z, w), z=y, w=x\right\}\right.$,

$\left.\left\{\langle\{\mathrm{y}, \mathrm{w}, \mathrm{z}\},\{\mathrm{R}(\mathrm{y}, \mathrm{x})\}, \varnothing\rangle_{\mathrm{L}}\right\}\right\rangle_{\mathrm{K}}$

e. $\quad$ a bride and groom $\rrbracket=$

$\left\langle\{\mathrm{x}, \mathrm{X}\},\left\{\operatorname{bride}(\mathrm{x}, \mathrm{y}), \mathrm{X}=\mathrm{x} \oplus \mathrm{y}, \operatorname{groom}^{-1}(\mathrm{z}, \mathrm{w}), \mathrm{z}=\mathrm{y}, \mathrm{w}=\mathrm{x}\right\}\right.$,

$\left.\left\{\langle\{\mathrm{y}, \mathrm{w}, \mathrm{z}\}, \varnothing, \varnothing\rangle_{\mathrm{L}}\right\}\right\rangle_{\mathrm{K}}$

f. $\quad$ a bride and groom $\rrbracket=$

$\left\langle\{\mathrm{x}, \mathrm{X}, \mathrm{z}\},\left\{\operatorname{bride}(\mathrm{x}, \mathrm{z}), \mathrm{X}=\mathrm{x} \oplus \mathrm{z}, \operatorname{groom}^{-1}(\mathrm{z}, \mathrm{x})\right\}, \varnothing\right\rangle_{\mathrm{K}}$ 
Example (64b) presents the relational semantics of a bride, as introducing a bride $\mathbf{x}$ in $\mathrm{U}(\mathrm{K})$, and a presupposed discourse referent $\mathbf{y}$ as the person she is the bride of in $\mathrm{A}(\mathrm{K})$. Given that the second conjunct groom also gets a relational semantics, it introduces two discourse referents in $\mathrm{A}(\mathrm{K})$, corresponding with the groom $(\mathbf{z})$ and the person he is the groom of $(\mathbf{w})$. We use the inverse relation groom $^{-1}$ here, just like we did in the N\&N constructions (cf. Sect. 3 above), so the anaphora resolution process internal to the coordinate phrase yields not only the identification of $\mathbf{z}$ to $\mathbf{y}$, but also the identification of $\mathbf{w}$ to $\mathbf{x}(64 \mathrm{~d})$. The matchmaking semantics of and in (64c) introduces a relation $\mathbf{R}$ as part of the presuppositional structure that is bound to the groom $^{-1}$ relation in $(64 \mathrm{e})$, and can thus be removed from $\mathrm{A}(\mathrm{K})$. The binding of $\mathbf{w}$ to $\mathbf{x}$, and the accommodation of $\mathbf{z}$ in $\mathrm{U}(\mathrm{K})$ allows emptying out $\mathrm{A}(\mathrm{K})$ entirely in (64f), which yields the final interpretation.

The analysis extends in an obvious way to conjunction of a bare singular noun with a plural DP in the first conjunct, as in the Spanish (54c), repeated here as (65):

$$
\begin{aligned}
& \text { Sus pómulos y nariz aparecían afilados. } \\
& \text { his }_{\mathrm{pl}} \text { cheeks }_{\mathrm{m} . \mathrm{pl}} \text { and nose } \mathrm{f}_{\mathrm{fsg}} \text { seemed }_{\mathrm{pl}} \text { sharp }_{\mathrm{pl}} \\
& \text { 'His cheeks and nose looked sharp.' }
\end{aligned}
$$

[Spanish]

Closest conjunct agreement follows from the fact that sus is in construction with pómulos in the syntactic structure [CoordP [DP sus pómulos] y nariz]. The matchmaking analysis establishes a relation between the nose and the cheeks, so that the nose also belongs to 'him', i.e. in the same face, cf. also the English (54e).

In sum, the analysis of DN\&N constructions as involving the syntactic structure [CoordP [DP D NP] and NP] immediately accounts for closest conjunct agreement between $\mathrm{D}$ and the first conjunct. The matchmaking analysis coupled with covert type-shifting formalized here as accommodation of a presupposed discourse referent accounts for the semantics of DN\&N constructions as involving a split interpretation. Note that the joint interpretation of DN\&N constructions involves a different syntactic structure, namely [DP D [CoordP NP and NP]]. So the 'special' syntactic structure [CoordP [DP D NP] and NP] correlates with a 'special' split semantics, whereas the standard syntactic structure of DP correlates with the standard semantics of conjunction in terms of plain set intersection.

The dynamic semantics of conjunction we developed also accounts for the fact that DN\&N constructions as in (66a) exist but N\&DN constructions as in (66b) do not:
a. the man and woman
b. *man and the woman
c. the man and his wife
d. her husband and the woman $_{j}$

The incremental interpretation within the coordinate phrase creates a left-right asymmetry between the first and the second conjunct, which we exploit for the dependency relation that is part of the matchmaking analysis: the woman in (66a) is a woman that is in some way or other connected to the man referred to in the first conjunct. This means we are taking dependency relations to be similar to anaphoric relations as expressed by the possessives in (66c) and (d). Example (66c) allows for an interpre- 
tation in which his refers to the man. This is possible because his wife is interpreted in a context that already contains a discourse referent for the man, so the pronoun is resolved against an accessible antecedent. Example (66d) however doesn't allow for an interpretation in which her refers to the woman. The discourse referent introduced by the woman is not accessible to the pronoun her, because it is not available from previous context. In our approach, the unacceptability of (66b) is related to the absence of an anaphoric reading of her in (66d) and to our assumption that DN\&N constructions are only possible if a dependency relation is established between the conjuncts in an incremental way.

Although we find DN\&N constructions in languages like English and Dutch, Heycock and Zamparelli (2005) claim that their counterparts in Spanish, French and Italian are infelicitous, while the judgments on German are "variable". Demonte et al. (2011), Demonte and Pérez-Jiménez (2012) have shown that DN\&N constructions are perfectly fine in Spanish, and studied close to 8000 attested examples of this construction from the Corpus de Referencia del Español Actual (CREA). It is harder to extend their claims to French, as we found only one example in Frantext. However, native speakers we consulted accept attested Internet examples such as the following:

Elle aura pour principales missions de « veiller au respect des droits et libertés dans le secteur audiovisuel, de garantir la transparence des médias et le pluralisme, de veiller à l'accomplissement des missions de service public incombant à la radio et télévision publiques et enfin d'empêcher toute forme de discrimination et (...). »

'Her principal missions will be to "ensure respect for the rights and freedoms in the audiovisual sector, to guarantee the transparency and pluralism of the media, to guarantee that the public radio and television can carry out their mission to serve the public, and finally to prevent any kind of discrimination and (...).",

As we will see in more detail in Sect. 6.3 below, plural marking on the post-nominal adjective unequivocally indicates wide scope over both nouns. Lexical factors probably play a role in the acceptability of DN\&N constructions. Our French consultants unanimously reject examples with relational nouns like bride and groom for instance. The CREA corpus mainly reveals DN\&N constructions with inanimate and abstract nouns. Note that Heycock and Zamparelli focus on examples with animate and human nouns, though. What the above suggests is that the facts are less straightforward than one might take them to be. As a consequence, it is far from obvious that adopting a binary parametric difference between English/Dutch-type and Spanish/French-type languages would do justice to the intricacies of the construction. We consequently refrain from building this type of difference into our analysis and await further in-depth studies of the role of lexical factors in bare coordination in the different languages involved.

\subsection{Adjectival modification}

The main focus of Arnold et al. (2006) and Demonte and Pérez-Jiménez (2012) is on closest conjunct agreement with adjectival modifiers, and the two papers build on extensive corpus research in Portuguese and Spanish respectively. Their findings in- 
dicate that pre-nominal adjectives agree with the first conjunct, whereas post-nominal adjectives either agree with the second conjunct, or take plural agreement. The three patterns are illustrated in (68)-(70) (examples from Demonte and Pérez-Jiménez 2012).

$$
\begin{aligned}
& \mathrm{Su} \text { verdadero desarrollo y expansión han venido } \\
& \text { its }_{\mathrm{sg}} \text { true }_{\mathrm{m} . \mathrm{sg}} \text { development }_{\mathrm{m} . \mathrm{sg}} \text { and expansion } \\
& \text { f.sg }_{\text {have }}
\end{aligned}
$$
ocurriendo a partir de la segunda mitad del presente siglo. taking place from the second half of.the current century 'Its true development and expansion have been taking place from the second half of the current century onwards.'

$$
\begin{aligned}
& \text {... el trigo y sorgo disponible no presentaron variantes. } \\
& \text { the }_{\mathrm{m} . \mathrm{sg}} \text { wheat }_{\mathrm{m} . \mathrm{sg}} \text { and sorghum } \\
& \mathrm{m} . \mathrm{sg}
\end{aligned}
$$

'The wheat and sorghum available did not show any change (in their levels).'

La agricultura y ganadería europeas se han ido the $_{\text {f.sg }}$ agriculture $_{\text {f.sg }}$ and stockbreeding f.sg $_{\text {European }}$ f.pl SE have $_{\mathrm{pl}}$ become industrializando.

industrializing

'European agriculture and stockbreeding have progressively become industrialised.'

With an adjective on the first noun, we almost exclusively find closest conjunct agreement, as in (68) (but see footnote 9 for potential exceptions). With post-nominal adjectives, about half the cases show number and gender agreement with the second conjunct (69), and the other half shows plural agreement with the coordinate phrase as a whole (70). If there are two post-nominal modifiers that differ in agreement, the first one shows closest conjunct agreement, and the last one shows plural agreement, as illustrated in (71):

$$
\begin{aligned}
& \text { La radio y televisión pública catalanas negocian hoy. } \\
& \text { the }_{\text {f.sg }} \text { radio }_{\text {f.sg }} \text { and television } \\
& \text { f.sg } \text { public }_{\text {f.sg }} \text { Catalonian } \\
& \text { 'The Catalonian public radio and television are negotiating today.' }
\end{aligned}
$$

Arnold et al. (2006) place an emphasis on post-nominal modification, but report similar patterns for Portuguese in a Google search. ${ }^{15}$

Arnold et al. as well as Demonte and Pérez-Jiménez emphasize that the adjective takes semantic scope over both conjuncts, independently of singular or plural agreement. The standard analysis of adjectives takes their scope to be related to their adjunction site. So the ambiguity of old men and women in (72) is resolved by the two syntactic structures of (72a) and (b):

old men and women

a. [old [men and women]]

b. [[old men] and [women]]

${ }^{15}$ Arnold et al. (2006) also investigate mismatches in gender agreement, which we ignore in this paper. 
The structure in (72a) corresponds with a wide scope interpretation of old over both conjuncts, whereas (72b) reflects narrow scope of old over the first conjunct only.

Under the structural account of scope proposed by Demonte et al. (2011), the pattern in (70) is completely regular: plural agreement on the post-nominal adjective is in line with semantic plurality of the coordinate phrase. So independently of the internal structure of DN\&N constructions, we can take the adjective to be adjoined at some level above the coordinate phrase, leading to the structure [[CoordP DN\&N] $\left.]_{p l} A_{p l}\right]$. In this configuration, agreement of the adjective with the plural CoordP relies on the same semantic agreement as we assumed for agreement with the verb in Sect. 5.3. ${ }^{16}$ Plural adjectives are not expected preceding the first noun, because there is no level at which the prenominal $\mathrm{A}$ can adjoin to agree with the plural CoordP under the structure $[\text { CoordP } \mathrm{DN} \& \mathrm{~N}]_{\mathrm{pl}}$.

The pattern in (69) is more puzzling for a structural account of scope. The puzzle lies in the fact that we cannot come up with a structure in which the adjective is adjoined high enough to take scope over the conjunction as a whole, while being low enough to establish singular agreement with the second conjunct. Demonte and Pérez-Jiménez (2012) postulate a post-syntactic process of linear adjacency, which makes agreement between the second conjunct and the adjective possible. They refer to Camacho (2003:98-99) who labels cases of partial agreement of postnominal adjectives in coordinated DPs as "PF agreement structures" since, in these cases, "partial or full agreement does not necessarily correlate with differences in interpretation."

We conclude that the behaviour of postnominal adjectives is compatible both with the structure [DP $\mathrm{D}_{\mathrm{sg}}$ [CoordP $\mathrm{NP}_{\mathrm{sg}}$ and $\left.\mathrm{NP}_{\mathrm{sg}}\right]$ ] proposed by Demonte and PérezJiménez (2012) and the structure [CoordP [DP D NP] and [NP NP]] we propose. The odds seem to change when we look at prenominal adjectives like in (68). Under the assumption that verdadero takes structural scope over desarrollo y expansion, this can be made to follow from an analysis that takes D to take scope over the whole coordination like the one proposed by Demonte et al. but not from one in which D only goes with the first conjunct like ours. The main problem Demonte et al. face is the mismatch between singular agreement with D and A, and plural agreement with the verb. They account for this in terms of two different sets of agreement features. In their approach, index features on the coordinate structure as a whole trigger plural agreement on the verb, so this can be viewed as an instance of semantic agreement. However, the (morpho-syntactic) concord features of the determiner and the adjective are checked by the first conjunct, because the coordinate structure doesn't carry concord features. So the mismatch in agreement is due to syntactic vs. semantic agreement patterns. The problem for our analysis is that the adjective is embedded in the first conjunct and cannot syntactically scope over the conjunction as a whole. Rather than giving up our analysis in favor of Demonte et al.'s, we question the assumption that verdadero is taking structural scope over desarrollo y expansión and propose an alternative analysis in terms of pragmatics.

\footnotetext{
${ }^{16}$ See Demonte and Pérez-Jiménez (2012) for a syntactically more sophisticated analysis of post-nominal adjectives in terms of reduced relative clauses.
} 
Before we develop the idea of pragmatic scope, note that we do not contest native speaker intuitions concerning wide scope. Example (73) gives a Dutch example in which the follow-up context spells out the wide scope reading in an explicit way:

Ook werd tijdens deze discoavond het mooist verklede meisje en jongen gekozen. Het mooiste verklede meisje was deze avond Nienke Pel en Pieter haar broer was de mooiste verklede jongen.

[Dutch] 'During this disco party, there was also an election for the best-dressed girl and boy. The girl who was dressed up the nicest this evening was Nienke Pel, and her brother Pieter was the boy who was dressed up the nicest.'

The fact that a wide scope interpretation is real does not entail that it comes from the structure, as it might arise as a pragmatic inference or accommodation. It is hard to establish the wide scope reading other than by introspection, and it seems quite possible that native speaker judgments are not strong enough to distinguish a linguistically encoded wide scope interpretation from a pragmatically natural wide scope reading.

In order for a pragmatic account of scope to be viable, we need to make sure that there are no linguistic arguments that unequivocally show that prenominal adjectives take structural scope over the conjunction by adjunction. We review the two arguments that we are aware of and argue that they are not decisive. The first comes from Demonte and Pérez-Jiménez (2012:12) who propose that "collective or symmetric adjectives like simultáneo, coincidente, similar, parecido, etc. (or, alternatively a collective operator licensing the collective reading of the predicate) must scope over a plural argument." If this were true, the acceptability of examples like (74) and (75) would constitute a linguistic argument in favour of a structural account of wide scope. Example (74) is taken from Demonte and Pérez-Jiménez (2012); Example (75) is adapted from the same paper and was suggested to us by an anonymous reviewer.

la destrucción y creación simultánea de la cultura del Nuevo Mundo 'the simultaneous destruction and creation of the culture of the New World'

Compra esta estantería. Su similar ${ }_{\text {sg }}$ altura $_{\text {.sg }}$ y anchura $_{\text {.sg }} \operatorname{son}_{\text {pl }}$ perfectas $_{\text {f.pl }}$ para tu salón.

'Buy this shelf. Its similar height and width are perfect for your living-room.'

If symmetric adjectives like simultánea and similar necessarily ranged over a plurality, (74) and (75) would show that there is a level of syntactic representation in which destrucción y creación and altura y anchura must form a phrase, presumably a CoordP, that the adjective adjoins to, and that is embedded in a DP. We however argue that symmetric adjectives don't impose structural plurality. Our argument is based on (76) and (77):

John bought a laptop. Peter bought a similar one today.

A twin brother will always defend his sister.

Examples (76) and (77) show that symmetric adjectives like similar and twin need not range over plural arguments but can also apply to singular ones as long as an anaphoric or cataphoric link can be established with another referent. In (76) this 
is John's laptop, in (77) the sister. On the basis of these and similar examples we conclude that the behaviour of collective and symmetric adjectives in examples like (74) and (75) cannot be taken as an argument for wide scope of adjectives at the structural level.

The second argument was provided to us by an anonymous reviewer, who notes that if scope is not structural, we would in principle expect adjectives in all positions in the DN\&N construction to be able to scope over both conjuncts. More specifically, we would expect the adjective rápida in (78) to be parallel to the adjective verdadero in (68) in being able to scope over the conjunction as a whole:

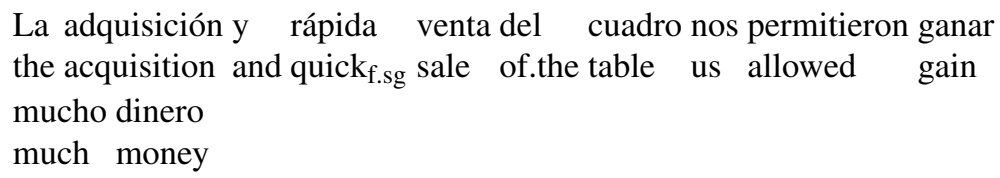
money.'

We agree with the reviewer that rápida in (78) does not scope over the conjunction as a whole. However, the contrast between examples like (78) and (68) is not necessarily an argument in favor of an analysis that takes verdadero in (68) to syntactically adjoin to the coordinate phrase. The counterargument we develop is based on the contrast between (79) and (80):

The man and his rich wife were present at the fundraiser.

Examples (79) and (80) form a minimal pair: rich in (79) modifies the second conjunct whereas it modifies the first conjunct in (80). On the most natural interpretation of (80) both the man and his wife can be considered rich whereas on the most natural interpretation of (79) it is only the wife who is considered to be rich. In both cases we are dealing with a conjunction of two full DPs, so the difference in interpretation cannot be attributed to adjunction of the adjective to the coordinate phrase. Instead, it relates to the dynamic nature of conjunction we established in Sect. 6.2: the second conjunct is interpreted in the discourse context updated with the information contributed by the first conjunct. Clearly, establishing a marital relation with a rich man implies a different information update from establishing a marital relation with just any man. Recall that the dependency relation we take to be part of the semantics of the DN\&N construction is similar to the anaphoric dependency with the possessive pronoun we see in (79) and (80). We conclude that the contrast between (78) and (68) is similarly not grounded in the syntax, but in the left-right asymmetry of incremental interpretation in conjunctions.

Now that we have established that there are no linguistic arguments in favour of an analysis that takes prenominal adjectives to take structural scope over the whole conjunction we can spell out an analysis in which wide scope is established via a pragmatic route. Example (81) works out the syntax-semantics interface of the example in (68) on the basis of the analysis of the DN\&N construction we developed in Sects. 6.1 and 6.2 and shows how pragmatic wide scope is compatible with it: 
Su verdadero desarrollo y expansión
a. [CoordP [DP $\mathrm{su}_{\mathrm{sg}}$ verdadero $_{\mathrm{m} . \mathrm{sg}}$ desarrollo $\left.\mathrm{m}_{\mathrm{m} . \mathrm{sg}}\right]$ y [NP expansión $\left.\mathrm{f}_{\mathrm{f} . \mathrm{sg}}\right]$ ]
b. $\llbracket$ su verdadero desarrollo $\rrbracket=\langle\{\mathrm{x}, \mathrm{w}\},\{\operatorname{verdadero}($ desarrollo $)(\mathrm{x}, \mathrm{w})\}$, $\varnothing\rangle_{\mathrm{K}}$
c. $\llbracket$ su verdadero desarrollo $\mathrm{y} \rrbracket=$ $\langle\{\mathrm{x}, \mathrm{w}, \mathrm{X}\},\{$ verdadero(desarrollo) $(\mathrm{x}, \mathrm{w}), \mathrm{X}=\mathrm{x} \oplus \mathrm{y}\}$, $\left.\left\{\langle\{\mathrm{y}\},\{\mathrm{R}(\mathrm{y}, \mathrm{x})\}, \varnothing\rangle_{\mathrm{L}}\right\}\right\rangle_{\mathrm{K}} \quad$ (matchmaking version of conjunction)
d. «su verdadero desarrollo y expansión》= $\langle\{\mathrm{x}, \mathrm{w}, \mathrm{X}\},\{$ verdadero(desarrollo) $(\mathrm{x}, \mathrm{w}), \mathrm{X}=\mathrm{x} \oplus \mathrm{y}, \operatorname{expansión}(\mathrm{z})$, $\left.\mathrm{z}=\mathrm{y}\},\left\{\langle\{\mathrm{y}, \mathrm{z}\},\{\mathrm{R}(\mathrm{y}, \mathrm{x})\}, \varnothing\rangle_{\mathrm{L}}\right\}\right\rangle_{\mathrm{K}}$
e. $\llbracket$ su verdadero desarrollo y expansión $\rrbracket=$ $\langle\{\mathrm{x}, \mathrm{w}, \mathrm{X}, \mathrm{z}\},\{$ verdadero(desarrollo) $(\mathrm{x}, \mathrm{w}), \mathrm{X}=\mathrm{x} \oplus \mathrm{z}$, expansión(z), R(z, x $)\}, \varnothing\rangle_{\mathrm{K}}$

(anaphora resolution and accommodation)

On the basis of the syntactic structure in (81a), we can interpret the first conjunct as referring to a discourse referent $\mathbf{x}$ for a true development in $(81 \mathrm{~b})$, related by the possessive $s u$ to some discourse referent $\mathbf{w}$. Given the definite nature of $s u$, both $\mathbf{x}$ and $\mathbf{w}$ are assumed to have been introduced earlier in the DRS. The incremental matchmaking semantics of conjunction in (81c), the interpretation of the second conjunct as introducing a presupposed discourse referent $\mathbf{z}$ in (81d) and a process of anaphora resolution and accommodation altogether lead to the final interpretation in (81e), in which there is a dependency relation of expansión on su verdadero desarrollo grounded in the incremental semantics of conjunction, which allows pragmatic spilling over of the information contributed by the adjective onto the second conjunct.

Summarizing, we observe that prenominal and post-nominal adjectives display different patterns of agreement, but share the possibility of scoping over the coordinated phrase as a whole. We follow Demonte and Pérez-Jiménez in their analysis of postnominal adjectives as ranging over the whole coordination, but argue that this has no consequences for our analysis of the DN\&N construction. As for our analysis of prenominal adjectives, we defend a pragmatic analysis of their wide scope behaviour grounded in the dynamic semantics of conjunction as a viable alternative to the structural account. We maintain our analysis of the DN\&N construction as having the structure [CoordP [DP D NP] and [NP NP]] in (58), while still accounting for the same facts as the ones covered by the analysis of Demonte et al. based on the structure [DP $\mathrm{D}_{\text {sg }}\left[\right.$ CoordP $\mathrm{NP}_{\text {sg }}$ and $\left.\mathrm{NP}_{\mathrm{sg}}\right]$ in (56).

\section{Conclusion}

This paper develops an analysis of the syntax-semantics interface of two types of split coordination structures we label the $N \& N$ and the DN\&N construction. We argue that both singulars and plurals can acquire a definite as well as an existential interpretation under bare coordination. We develop a special matchmaking semantics for split conjunction as an extension of the standard set intersection used for joint conjunction. The matchmaking relation underlies the lexical and pragmatic frames in natural coordination. 
The restriction of $\mathrm{N} \& \mathrm{~N}$ constructions to split readings correlates with the absence of a DP projection on top of the coordinate phrase in languages like English, Spanish, and Dutch. The syntactic restriction is embedded in the OT typology of number and article use developed by de Swart and Zwarts (2008, 2010).

Split conjunction is also found in DN\&N constructions. We develop an extension of the matchmaking semantics that accounts for them. DN\&N constructions imply a dynamic semantics of conjunction, and accommodate a discourse referent for the second conjunct as related to the (discourse) referent introduced by the DP in the first conjunct. The agreement patterns of both prenominal and postnominal adjectives can be accounted for under this analysis.

The main advantage of the current proposal is that it offers a unified account of the syntax-semantics interface of both $\mathrm{N} \& \mathrm{~N}$ and DN\&N constructions, while respecting the differences between these coordinate structures. We do so in a framework which avoids positing functional projections that have no overt material in them, and which can handle cross-linguistic variation. Furthermore, we develop a polysemous semantics of and as desired, and establish a connection between the matchmaking semantics and the notion of natural coordination used in lexical semantics and pragmatics.

Acknowledgements We would like to thank Joost Zwarts, Yoad Winter, Christina Märzhäuser, Louise McNally, Martin Everaert, Hagit Borer, Ana Aguilar-Guevara, Marjo van Koppen, five anonymous reviewers, and our audiences at the BKL Linguists' Day (Brussels), a definiteness workshop (Oslo), Going Romance (Leiden), as well as the linguistics colloquium of the Universitàt Autonoma de Barcelona and the LyCC seminar at the Centro de Ciencias Humanas y Sociales CSIC in Madrid for insightful discussions and challenges. For native speaker judgments on Mandarin Chinese we thank Xiaoli Dong and Yuning Sun. For native speaker judgments on Russian we thank Olga Borik. This research was carried out as part of the project "Weak referentiality: bare nouns at the lexicon-syntax-semantics interface" and we gratefully acknowledge the support of the Netherlands Organization for Scientific Research (NWO, grant \#360-70-340).

Open Access This article is distributed under the terms of the Creative Commons Attribution License which permits any use, distribution, and reproduction in any medium, provided the original author(s) and the source are credited.

\section{References}

de Almeida Torres, Artur. 1981. Moderna gramática expositiva da língua portuguesa. Sao Paulo: Martins Fontes.

Arnold, Doug, Louisa Sadler, and Aline Villavicencia. 2006. Portuguese: corpora, coordination and agreement. In Roots: linguistics in search of its evidential base, eds. Sam Featherston, and Wolfgang Sternefeld. Vol. 96 of Studies in generative grammar, 9-28. The Hague: de Gruyter.

Barwise, Jon, and Robin Cooper. 1981. Generalized quantifiers and natural language. Linguistics and Philosophy 4: 159-219.

Borer, Hagit. 2005. Structuring sense, Vol. 1: In name only. Oxford: Oxford University Press.

Borsley, Robert D. 2005. Against ConjP. Lingua 115: 461-482.

Bošković, Željco. 2008. What will you have, DP or NP? North East Linguistic Society (NELS) 37: 101114.

de Bruin, Jos, and Remko Scha. 1988. The interpretation of relational nouns. In Association for computational linguistics (ACL), Morristown, NJ, ed. Steven Bird, 25-32.

Camacho, José. 2003. The structure of coordination. Conjunction and agreement phenomena in Spanish and other languages. Dordrecht: Kluwer Academic.

Chaves, Rui P. 2008. Linearization-based word-part ellipsis. Linguistics and Philosophy 31: 261-307. 
Chierchia, Gennaro. 1998. Reference to kinds across languages. Natural Language Semantics 6: 339-405.

Condoravdi, Cleo. 1994. Descriptions in context. Yale University dissertation.

Cooper, Robin. 1979. Model theory for a fragment of English syntax. Ms. Madison, Wisconsin.

Dalrymple, Mary, and Irina Nikolaeva. 2006. Syntax of natural and accidental coordination. Evidence from agreement. Language 82(4): 824-849.

Dayal, Veneeta. 2011. Bare noun phrases. In Semantics: an international handbook of natural language meaning, eds. Claudia Maienborn, Klaus von Heusinger, and Paul Portner, Vol. II, 1088-1108.

Delfitto, Denis, and Jan Schroten. 1991. Bare plurals and the number affix in DP. Probus 3: 155-185.

Demonte, Violeta, Héctor Fernández-Alcalde, and Isabel Pérez-Jiménez. 2011. On the nature of nominal features. Agreement mismatches in Spanish conjoined structures. In Romance linguistics 2010: selected papers from the 40th linguistic symposium on romance languages, Seattle, Washington, ed. Julia Herschensohn, 177-190. Amsterdam: Benjamins.

Demonte, Violeta, and Isabel Pérez-Jiménez. 2012. Closest conjunct agreement in Spanish DPs. Syntax and beyond. Folia Lingüística 46(1): 21-74.

Espinal, M. Teresa, and Louise McNally. 2010. Bare singular nominals and incorporating verbs in Spanish and Catalan. Journal of Linguistics 47: 87-128.

Farkas, Donka, and Henriëtte de Swart. 2003. The semantics of incorporation: from argument structure to discourse transparency. Stanford: CSLI Publications.

von Fintel, Kai. 1999. NPI-licensing, Strawson-entailment, and context dependency. Journal of Semantics 16: 97-148.

Haiman, John. 1983. Iconic and economic motivation. Language 59(4): 781-819.

Halle, Morris, and Alec Marantz. 1993. Distributed morphology and the pieces of inflection. In The view from building 20. Essays in linguistics in honour of Sylvain Bromberger, eds. Ken Hale, and Samuel J. Keyser, 111-176. Cambridge: MIT Press.

Haspelmath, Martin. 2007. Coordination. In Language typology and linguistic description, ed. Timothy Shopen. Cambridge: Cambridge University Press.

Hendriks, Petra, Helen de Hoop, Irene Krämer, Henriëtte de Swart, and Joost Zwarts. 2010. Conflicts in interpretation. Sheffield: Equinox Publishing.

Heycock, Caroline, and Roberto Zamparelli. 2003. Coordinated bare definites. Linguistic Inquiry 34: 443469.

Heycock, Caroline, and Roberto Zamparelli. 2005. Friends and colleagues. Plurality, coordination and the structure of DP. Natural Language Semantics 13: 201-270.

de Hoop, Helen. 1996. Case configuration and noun phrase interpretation. New York: Garland. Revised and updated version of dissertation (1992, University of Groningen).

Kager, René. 1999. Optimality theory. Cambridge: Cambridge University Press.

Kamp, Hans, and Uwe Reyle. 1993. From discourse to logic. Dordrecht: Kluwer Academic.

Keenan, Edward. 1987. A semantic definition of indefinite NP. In The representation of (in)definiteness, eds. Eric Reuland and Alice ter Meulen, 286-317. Cambridge: MIT Press.

King, Tracy, and Mary Dalrymple. 2004. Determiner agreement and noun conjunction. Journal of Linguistics 40(1): 69-104.

Kiparsky, Paul. 1973. Elsewhere in phonology. In A festschrift for Morris Halle, eds. Stephen R. Anderson, and Paul Kiparsky. New York: Holt, Rinehart and Winston.

Kuo, Jenny Yi-chun. 2008. A pragmatic approach to the interpretations of Mandarin bare nouns. Journal of Pragmatics 40(6): 1082-1102.

Laca, Brenda. 1999. Presencia y ausencia de determinante. In Gramática descriptiva de la lengua española, eds. Ignacio Bosque, and Violeta Demonte. Vol. 1 of Real Academia Española, Collección Nebrija y Bello, 891-929. Madrid: Espasa Calpe.

Lambrecht, Knud. 1984. Formulaicity, frame semantics and pragmatics in German binomial expressions. Language 60(4): 753-796.

Le Bruyn, Bert. 2010. Indefinite articles and beyond. Utrecht: LOT.

Le Bruyn, Bert, Henriëtte de Swart, and Joost Zwarts. 2011. Mass-count distinctions in bare PPs. Ms. Utrecht University.

Lombardi, Linda. 1999. Positional faithfulness and voicing: assimilation in optimality theory. Natural Language and Linguistic Theory 17: 267-302.

Longobardi, Giuseppe. 1994. Reference and proper names: a theory of N-movement in syntax and logical form. Linguistic Inquiry 25: 609-665.

Märzhäuser, Christina. 2013. Coordinated bare nouns in French, Spanish and European Portuguese. In New perspectives on bare noun phrases in romance and beyond, eds. Johannes Kabatek and Albert Wall, 283-300. Amsterdam: Benjamins. 
McNally, Louise. 1998. Existential sentences without existential quantification. Linguistics and Philosophy 21: 353-392.

McNally, Louise, and Gemma Boleda. 2004. Relational adjectives as properties of kinds. In Empirical issues in syntax and semantics. eds. Olivier Bonami, and Patricia Cabredo Hofherr, Vol. 5, 179-196.

McNally, Louise. 2011. Existential sentences. In Semantics: an international handbook of natural language meaning, eds. Claudia Maienborn, Klaus von Heusinger, and Paul Portner, 1829-1848. Berlin: de Gruyter.

Milsark, Gary. 1974. Existential sentences in English. MIT dissertation. Reprinted: New York: Garland, 1979.

Partee, Barbara, and Mats Rooth. 1983. Generalized conjunction and type ambiguity. In Meaning, use, and interpretation of language, eds. Rainer Bäuerle, Christoph Schwarze, and Armin von Stechow, 361-383. Berlin: de Gruyter.

Partee, Barbara H. 1987. Noun phrase interpretation and type-shifting principles. In Studies in Discourse Representation Theory and the theory of generalized quantifiers, eds. Jeroen A.G. Groenendijk, Dick de Jongh, Martin J.B. Stokhof, and Walter de Gruyter, 115-143. Dordrecht: Foris.

Postma, Gertjan. 1995. Zero-semantics - a study of the syntactic conception of quantificational meaning. Unpublished PhD diss., Leiden University.

Roodenburg, Jasper. 2004. French bare nouns are not extinct. Linguistic Inquiry 35: 301-313.

Roodenburg, Jasper. 2005. The interpretations of coordinated bare nouns in French. In Conference of the Student Organization of Linguistics in Europe (ConSOLE) 11. Leiden University.

Van der Sandt, Rob A. 1992. Presupposition projection as anaphora resolution. Journal of Semantics 9(4): 333-377.

Van der Sandt, Rob A., and Bart Geurts. 1991. Presupposition, anaphora, and lexical content. In Text understanding in LiLOG, eds. Otthein Herzog and Claus Rollinger, 259-296. Berlin: Springer.

Staroverov, Peter. 2007. Relational nouns and reciprocal plurality. Semantics and Linguistic Theory (SALT) 17: 300-316.

Stowell, Tim. 1981. Complementizers and the empty category principle. In North East Linguistics Society (NELS), eds. Victoria Burke and James Pustejovsky, Vol. 11, 345-363. Amherst: GLSA.

de Swart, Henriëtte. 2001. Weak readings of indefinites: type-shifting and closure. The Linguistic Review 18: 69-98.

de Swart, Henriëtte, Yoad Winter, and Joost Zwarts. 2007. Bare nominals and reference to capacities. Natural Language and Linguistic Theory 25(1): 195-222.

de Swart, Henriëtte, and Joost Zwarts. 2008. Article use across languages: an OT typology. In Sinn und Bedeutung (SuB12), University of Oslo, ed. Atle Grønn, Vol. 12, 628-644.

de Swart, Henriëtte, and Joost Zwarts. 2009. Less form-more meaning: why bare singular nouns are special. Lingua 119(2): 280-295.

de Swart, Henriëtte, and Joost Zwarts. 2010. Optimization principles in the typology of number and articles. In Handbook of linguistic analysis, eds. Bernd Heine, and Heiko Narrog, 555-581. Oxford: Oxford University Press.

Wälchli, Bernard. 2005. Co-compounds and natural coordination. Oxford: Oxford University Press.

Winter, Yoad. 2001. Flexible principles in Boolean semantics. Cambridge: MIT Press.

Zamparelli, Roberto. 2005. The structure of (in)definiteness. Lingua 115: 915-936.

Zamparelli, Roberto. 2011. Coordination. In Semantics: an international handbook of natural language meaning, eds. Claudia Maienborn, Klaus von Heusinger, and Paul Portner, Vol. II. Berlin: de Gruyter.

Zwarts, Joost. 2009. Bare constructions in Dutch. Ms. Utrecht University. 